\title{
Canadian Rheumatology Association Recommendations for Pharmacological Management of Rheumatoid Arthritis with Traditional and Biologic Disease-modifying Antirheumatic Drugs
}

\author{
VIVIAN P. BYKERK, POONEH AKHAVAN, GLEN S. HAZLEWOOD, ORIT SCHIEIR, ANNE DOOLEY, \\ BOULOS HARAOUI, MAJED KHRAISHI, SHARON A. LECLERCQ, JEAN LÉGARÉ, DIANE P. MOSHER, \\ JAMES PENCHARZ, JANET E. POPE, JOHN THOMSON, CARTER THORNE, MICHEL ZUMMER, \\ and CLAIRE BOMBARDIER
}

ABSTRACT. Objective. The Canadian Rheumatology Association (CRA) has developed recommendations for the pharmacological management of rheumatoid arthritis (RA) with traditional and biologic disease-modifying antirheumatic drugs (DMARD) in 2 parts. Part 1 is reported here.

Methods. The CRA Therapeutics Committee assembled a national working group of RA clinical experts, researchers, patient consumers, and a general practitioner. Treatment questions were developed a priori based on results of a national needs assessment survey. A systematic review of all clinical practice guidelines and consensus statements regarding treatment with traditional and biologic DMARD in patients with RA published between January 2000 and June 2010 was performed in Medline, Embase, and CINAHL databases, and the grey literature. Guideline quality was assessed by 2 independent reviewers, and guideline characteristics, recommendations, and supporting evidence from observational studies and randomized controlled trials were synthesized into evidence tables. The full working group reviewed the evidence tables and developed recommendations using a modified Delphi technique.

Results. Five overarching principles and 26 recommendations addressing general RA management strategies and treatment with glucocorticoids and traditional and biologic DMARD were developed for rheumatologists, other primary prescribers of RA drug therapies, and patients with RA.

Conclusion. These recommendations were developed based on a synthesis of international guidelines, supporting evidence, and expert consensus considering the Canadian healthcare context with the intention of promoting best practices and improving healthcare delivery for persons with RA. (First Release Sept 15 2011; J Rheumatol 2012;39:1559-82; doi:10.3899/jrheum.110207)

Key Indexing Terms: RHEUMATOID ARTHRITIS DRUG THERAPY CONSENSUS DEVELOPMENT CONFERENCE

PRACTICE GUIDELINES QUALITY OF HEALTHCARE

\footnotetext{
From the Department of Rheumatology, Mount Sinai Hospital, Toronto, Ontario; Division of Rheumatology, Brigham and Women's Hospital, Boston, Massachusetts, USA; Department of Health Policy, Management and Evaluation, University of Toronto; Toronto General Research Institute, University Health Network; Department of Public Health Sciences, University of Toronto; Arthritis Community Research and Evaluation Unit, Toronto Western Research Institute, Toronto, Ontario; Department of Medicine, University of Montreal, Montreal, Quebec; Division of Rheumatology, Memorial University of Newfoundland, St. John's, Newfoundland; Division of Rheumatology, University of Calgary, Calgary, Alberta; Credit Valley Family Health Team, Credit Valley Hospital, Mississauga, Ontario; Division of Rheumatology, University of Western Ontario, London, Ontario; Division of Rheumatology, University of Ottawa, Ottawa, Ontario; The Arthritis Program, Southlake Regional Health Centre, Newmarket, Ontario; Service de Rhumatologie, Hôpital Maisonneuve-Rosemont, Montreal, Quebec; and Division of Rheumatology, University of Toronto, Toronto, Ontario, Canada.

Supported by a Canadian Institutes of Health Research (CIHR) Scoping Reviews and Research Syntheses Grant and matched funds from the Canadian Rheumatology Association (CRA). O. Schieir is supported by a Fonds de la Recherche en Santé de Québec (FRSQ) Doctoral Research Award. Dr. Akhavan is supported by a UCB/CRA/TAS Post-Graduate Rheumatology Fellowship. Dr. Hazlewood is supported by a UCB/CRA/TAS Post-Graduate Rheumatology Fellowship and an Alberta Heritage Foundation for Medical Research Clinical Fellowship. Dr.
}

Bombardier holds a Pfizer Chair and a Canada Research Chair in Knowledge Transfer for Musculoskeletal Care.

V.P. Bykerk, MD, FRCPC, Assistant Professor, University of Toronto, Instructor, Harvard University, Department of Rheumatology, Mount Sinai Hospital; P. Akhavan, MD, FRCPC; G.S. Hazlewood, MD, FRCPC; O. Schieir, MSc; A. Dooley, BA; B. Haraoui, MD, FRCPC, Clinical Associate Professor of Medicine, University of Montreal; M. Khraishi, $M B, B C h, F R C P C$, Clinical Professor of Medicine, Memorial University of Newfoundland, Medical Director (Rheumatology), Nexus Clinical Research; S.A. LeClercq, MD, FRCPC, Clinical Associate Professor, Division of Rheumatology, University of Calgary; J. Légaré, Volunteer, Arthritis Patient Advocate; D.P. Mosher, MD, FRCPC, Division Chief, Rheumatology, University of Calgary; J. Pencharz, MD, MSc; J.E. Pope, $M D, M P H, F R C P C$, Professor, Schulich School of Medicine and Dentistry, University of Western Ontario; C. Thorne, MD, Director, The Arthritis Program, Southlake Regional Health Centre; J. Thomson, MD, FRCPC, Assistant Professor, Department of Medicine, University of Ottawa; M. Zummer, MD, FRCPC, Associate Professor, Department of Medicine, University of Montreal, Hôpital Maisonneuve-Rosemont; C. Bombardier, MD, FRCPC, Professor, Department of Rheumatology, Mount Sinai Hospital, Department of Health Policy, Management, and Evaluation, University of Toronto, and Division of Clinical Decision Making and Health Care, Toronto General Research Institute, University Health Network. Personal non-commercial use only. The Journal of Rheumatology Copyright @ 2012 . All rights reserved. 
Address correspondence to Dr. V. Bykerk, Mount Sinai Hospital, The Joseph and Wolfe Lebovic Building, The Rebecca McDonald Centre for Arthritis and Autoimmune Disease, 2-005 60 Murray Street, Box 5, Toronto, ON M5T3L9.E-mail:vbykerk@mtsinai.on.ca

FULL RELEASE ARTICLE. For details see reprints/permissions at jrheum.org

Accepted for publication June 1, 2011.

Recommendations were based on the highest quality of evidence available at the time the working group undertook this review, and are intended to promote best practices and improve healthcare delivery for persons with rheumatoid arthritis (RA). Recommendations, however, should not be interpreted as rigid or legal standards, nor are they meant to replace the clinical judgement of specialists and other trained RA healthcare providers acting according to the individual needs of the patient and the unique clinical circumstance.

Rheumatoid arthritis is a chronic autoimmune disease characterized by inflammation, pain, stiffness, and progressive joint destruction currently affecting about 300,000 Canadians ${ }^{1}$. In addition to higher rates of morbidity and mortality, persons with RA experience significant financial and productivity losses, as well as symptom, emotional and social burdens affecting their health-related quality of life $e^{2,3}$.

The pharmacologic management of RA has progressed substantially over the last decade. Earlier and more aggressive treatment strategies with traditional disease-modifying antirheumatic drugs (DMARD) and the more recent introduction of biologic therapies that target specific mechanisms of inflammation have been shown to alter the clinical course of RA and slow or halt radiographic progression. The most commonly prescribed traditional DMARD are methotrexate (MTX), leflunomide (LEF), sulfasalazine (SSZ), and hydroxychloroquine (HCQ).

Biologic therapies currently approved for use in Canada include (1) tumor necrosis factor inhibitors [anti-TNF; etanercept (ETN), infliximab (IFX), adalimumab (ADA), golimumab (GOL), and certolizumab pegol (CTZ)]; (2) T cell costimulatory inhibitor [abatacept (ABAT)]; (3) B lymphocyte-depleting agent [rituximab (RTX)]; (4) interleukin 6 (IL-6) antagonist [tocilizumab (TCZ)]; and (5) IL-1 antagonist (anakinra), although anakinra is used far less often in RA due to side effects and its decreased magnitude of benefit relative to other biologic agents ${ }^{1,4}$.

Need for Canadian guidance. There are outstanding questions regarding the optimal use of traditional DMARD, and newer biologic therapies, and the international literature regarding the efficacy and potential harms of RA drug therapies continues to grow exponentially. High quality clinical practice guidelines can be a useful knowledge tool to help translate evidence-based healthcare to the appropriate end-users in an accessible and manageable format ${ }^{5}$. There are several published international RA guidelines; however, many individual guidelines have limited scope, and vary in quality and/or timeliness of evidence reviewed $^{6,7}$. Canadian RA healthcare providers, decision makers, and consumers need guidance that has been developed taking into account the Canadian practice setting.

The Canadian Rheumatology Association (CRA) has developed recommendations for the pharmacological management of RA with traditional and biologic DMARD in 2 parts, part 1 providing focused treatment guidance and part 2 providing focused guidance on safety aspects of the pharmacological management of RA.

Objective. The objective was to develop Part 1 of CRA recommendations for the pharmacological treatment of RA with traditional and biologic DMARD based on a synthesis of international guidelines, supporting evidence, and expert consensus of a national Canadian RA working group.

Target patient population. The target population for these recommendations are adult (age $\geq 18$ years) patients with $\mathrm{RA}$ according to prior $^{8}$ and current classification criteria ${ }^{9}$ and patients with early inflammatory arthritis suspected of having RA by a trained RA healthcare provider.

Target users. The target users of these recommendations are rheumatologists or other primary prescribers of RA medications who are treating patients with RA in community and academic practice settings and RA patient consumers. Recommendations may also be of interest to other provincial and federal RA stakeholders and decision makers.

What is covered. These recommendations are the first of 2 parts and include 26 recommendations across the following RA treatment domains: general RA management strategies; treatment with glucocorticoids (GC); treatment with traditional DMARD; and treatment with biologic DMARD. Specific key questions are presented in Table 1.

What is not covered. The present document does not include recommendations for nonpharmacological treatments or for other adjunctive therapies for patients with RA, including nonsteroidal antiinflammatory drugs (NSAID). Although costs were embedded in the discussion of each recommendation, a formal cost-effectiveness analysis was not performed. Further, there is a lack of direct comparative effectiveness data for RA drug therapies. Detailed guidance for safety and monitoring of traditional and biologic DMARD is published separately in a second instalment of Canadian recommendations ${ }^{10}$.

Funding and conflict of interest. This guidance was funded through the Canadian Institutes of Health Research (CIHR) and matched funds from the Canadian Rheumatology Association (CRA). Potential conflicts for each working group member including industry funding, consultancies, commercial interests, and direct involvement in any guidelines included in the systematic review for the last 3 years are shown in Appendix 1.

Applicability/dissemination strategies. These recommendations were endorsed by the CRA on January 17, 2011, for a period of 2 years. Moreover, Canadian recommendations, Personal non-commercial use only. The Journal of Rheumatology Copyright @ 2012 . All rights reserved. 
Table 1. Key questions regarding the pharmacological treatment of patients with rheumatoid arthritis (RA).

General RA treatment strategies

1. What are the goals of treatment?

2. What are poor prognostic features that should be measured at baseline to inform treatment decisions?

3. How often should disease activity be monitored?

4. How often should the treatment strategy be adjusted in patients with RA?

5 . How often should radiographs be ordered?

6. Should therapy be changed in RA patients with adequate clinical response but with unequivocal x-ray progression?

Treatment with glucocorticoids

7. What is the role of glucocorticoids in the management of RA?

Treatment with traditional DMARD (disease-modifying antirheumatic drugs)

8. When should DMARD be started?

9. Which DMARD should be used first?

10. Which investigations should be ordered prior to starting treatment with MTX?

11. What is the optimal dosing strategy for MTX?

12. When should combination therapy with traditional DMARD be used?

13. Which traditional DMARD combinations are preferred?

14. Should leflunomide be used in combination with MTX?

Treatment with biologic DMARD

15. In patients being considered for treatment with biologic DMARD, how should an inadequate response to traditional DMARD be defined?

16. Which investigations should be ordered prior to starting treatment with biologic DMARD?

17. Should MTX be coprescribed with biologic DMARD?

18. When should anti-TNF therapy be used in the treatment of patients with RA?

19. When should abatacept be used in the treatment of patients with RA?

20. When should rituximab be used in the treatment of patients with RA?

21 . How should patients be retreated with rituximab?

22. When should tocilizumab be used in the treatment of patients with RA?

23. Which therapeutic strategy is recommended after failure of 1 anti-TNF?

24. Which therapeutic strategy is recommended after failure of 2 anti-TNF?

25. Which therapeutic strategy is recommended after failure of abatacept, rituximab, or tocilizumab?

26. Should therapy be tapered or withdrawn in RA patients who achieve sustained remission?

MTX: methotrexate; anti-TNF: tumor necrosis factor inhibitor.

supplementary materials including the detailed search strategy, overview and evidence tables, and tools to aid rheumatology healthcare providers in implementing these recommendations will be made available through the CRA website (http://www.rheum.ca). Recommendations will be reviewed after the 2-year period to determine if they remain current in the face of emerging evidence.

\section{MATERIALS AND METHODS}

Approach to guideline development. De novo guideline development is both time-consuming and costly (funds, expertise, and human resources). The ADAPTE collaboration, an international group of guideline developers and implementers, has developed a systematic framework for adapting guidelines produced for use in one cultural and organizational context to be used in a different cultural and organizational context (see http://www.adapte.org). As there are several RA guidelines published by international rheumatology associations and policy-making organizations, a modified approach based on the ADAPTE framework ${ }^{11,12}$ was used to systematically identify, appraise, synthesize, and adapt international RA guidelines for use in the Canadian healthcare context.

Assembly of the Canadian RA Working Group. We assembled a nationally representative working group of 16 Canadian RA stakeholders (all are coauthors) on behalf of the CRA. Representatives from all relevant domains of expertise were sought including clinical (rheumatology and primary care), methodological (epidemiologists/health services researchers/information specialist), rheumatology research trainees, and patient consumers. Rheumatologist experts were representatives of the CRA Therapeutics Committee, key opinion leaders in RA, and/or representatives of regional/local rheuma- tology associations across the country, from both academic and community settings. Consumer experts had served on multiple RA research projects and decision-making panels and were active members of numerous patient societies including (but not limited to) The Arthritis Society (TAS), the Canadian Arthritis Patient Alliance (CAPA), and the Arthritis Consumer Experts (ACE). Guideline methodology was developed and executed by a central methods team (CMT) made up of 2 rheumatologist experts and research scientists $(\mathrm{CB}, \mathrm{VB}), 2$ rheumatology research trainees $(\mathrm{GH}, \mathrm{PA})$, and a project coordinator (OS). Following an integrated knowledge translation approach, the full working group (RA experts, patient experts, and primary care and methods experts) were involved in each phase of guideline development by attending working group meetings and/or contributing to e-mail discussions, revising recommendations, participating in consensus voting procedures, and contributing to drafts of the document. No representatives of pharmaceutical companies were involved in any phase of guideline development.

Defining the scope. A comprehensive list of potential key questions was developed a priori. Candidate key questions were selected from results of a national needs assessment survey of Canadian rheumatology professionals $(n=164)$ performed in preparation for guideline development ${ }^{13}$. Additional questions were identified from executive summaries of CRA Therapeutics Committee meetings and published international guidelines. The full working group reviewed the list of candidate questions at a face-to-face meeting and selected 26 priority treatment questions to be addressed by consensus (Table 1).

Search criteria. Included studies were clinical practice guidelines (CPG) and consensus statements (CS) with recommendations for traditional and biologic DMARD currently approved for use in Canada for adult RA populations, and published in English or French between January 2000 and June 2010. Both CPG and CS were included in order to collect the most common prescribed and applied resources used to inform clinical decision-making ${ }^{6}$.

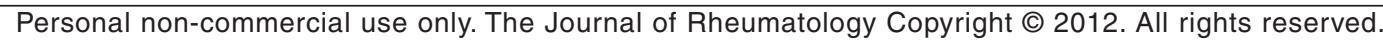


Guidelines that referred to other rheumatic disease populations in addition to RA were included if the major population of interest was RA. Articles were excluded if they were systematic or narrative reviews with recommendations made by a single expert and if they did not address at least one key question posed by the working group. Guidelines were also excluded if they were deemed to be of very poor methodological quality using a validated guideline quality appraisal instrument ${ }^{14}$. All Canadian guidelines were included given their relevance to the Canadian practice setting.

Search strategy. We performed a systematic search for studies according to the inclusion/exclusion criteria detailed above in Medline, Embase, and CINAHL databases combining keyword and major subject headings for: RA, class and specific drug names for traditional DMARD and biologic agents, and guidelines and consensus statements published in English or French between January 2000 and July 2009. In conjunction with the database search, we performed a comprehensive grey literature search of rheumatology societies, guideline clearinghouses, and bibliographic hand searches according to published methods ${ }^{15}$. All search results were screened by 2 independent rheumatology research trainees $(\mathrm{GH}, \mathrm{PA})$, and disagreements were resolved by consensus. Search results were updated using the same procedures outlined above to include guidelines published up to and including June 2010. A diagram of search results is presented in Figure 1.

Appraisal of guideline quality. Guideline quality was assessed using a validated questionnaire, the Appraisal of Guidelines Research and Evaluation (AGREE) instrument ${ }^{11}$. The AGREE instrument consists of 23 questions across 6 domains: scope and purpose, stakeholder involvement, rigor of development, clarity and presentation, applicability, and editorial independence. Domain scores are then used to formulate a single-item overall assess- ment of the guideline as "Recommend" (R), "Recommend with Provisos" $\left(\mathrm{R}^{*}\right)$, or "Would Not Recommend" (WNR) ${ }^{11}$.

Grading evidence. Systems for assigning levels of evidence differed across guidelines. In order to reconcile these differences we translated each guideline's grading system onto a custom system for assigning levels of evidence simplified from that developed by the Scottish Intercollegiate Guideline Network (SIGN) ${ }^{16}$. A level of evidence and strength of recommendation was assigned for each recommendation according to this custom grading system (Table 2).

Evidence synthesis. Tables of included guidelines containing descriptive characteristics (guideline developer, country, year, topic, target audience, funding sources) and detailed AGREE domain scores were prepared for each subsection of the guideline. Evidence tables containing guideline characteristics (developer and year), recommendations, AGREE summary scores, and supporting evidence were prepared for each key question.

Development of recommendations. For each key question, the full working group was presented with an overview and evidence table summarizing recommendations and supporting evidence from international guidelines. If the panel agreed with at least one existing recommendation, a Canadian recommendation was developed by adapting and rewording existing recommendations. Recent guidelines of high methodological quality were emphasized. Supporting evidence from observational studies and randomized controlled trials (RCT) referenced by the guideline was reviewed in detail. If the panel did not agree with at least one recommendation provided by the guidelines, a recommendation was developed by consensus after considering available evidence cited by relevant guidelines. In special circumstances, additional primary literature identified through supplementary manual literature searches

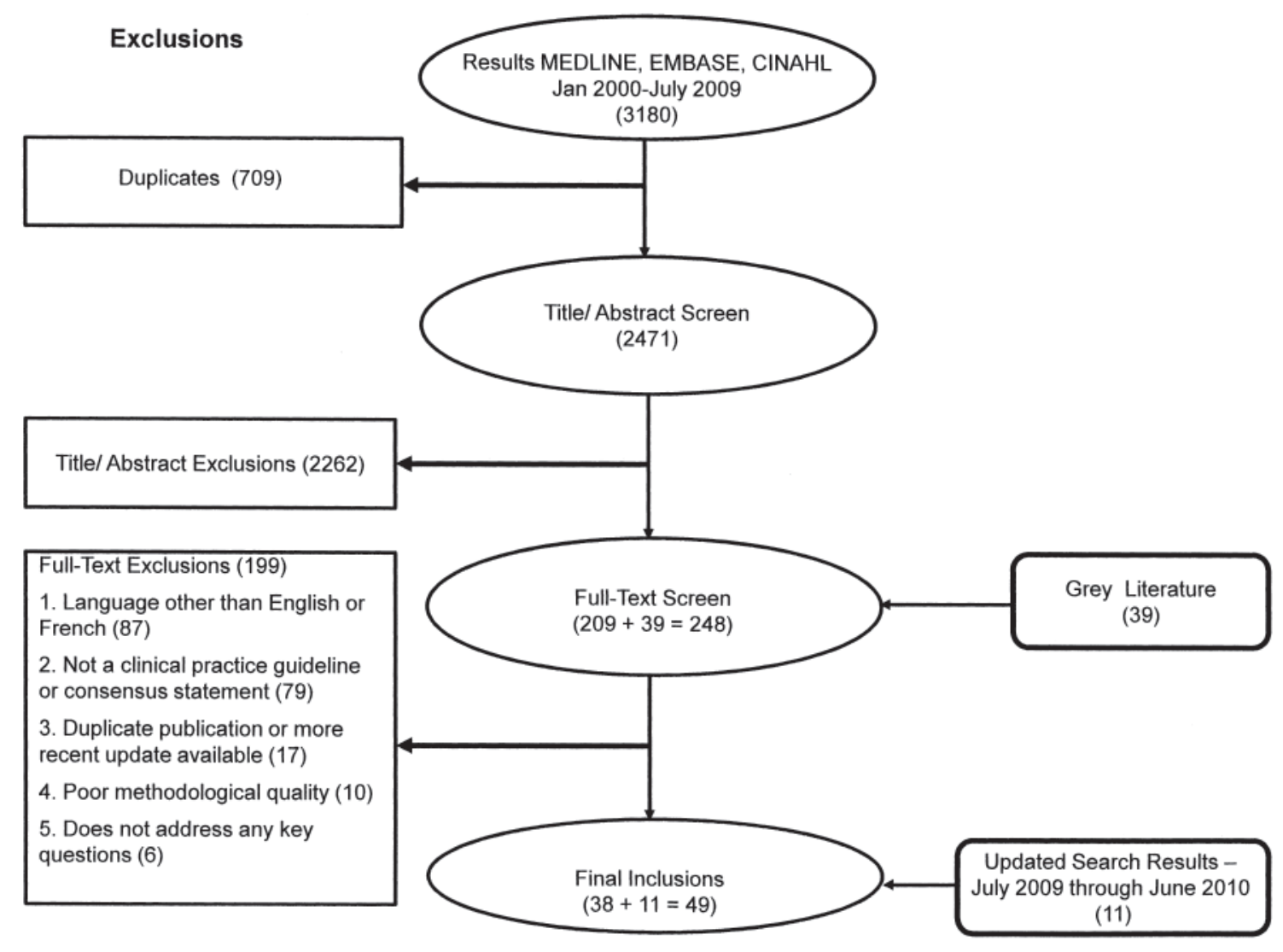

Figure 1. Steps in the systematic review of international guidelines on the pharmacological management of rheumatoid arthritis. 
Table 2. Custom system for assigning level of evidence and strength of recommendation.

Levels of Evidence $\quad$ Strength of Recommendation

I Metaanalyses, systematic reviews of RCT, or individual RCT

II Metaanalysis, systematic reviews of observational studies (cohort/case control studies), or individual observational studies OR

RCT subgroup/post-hoc analyses

III Nonanalytic studies, e.g., case reports, case series

IV Expert opinion

NR Recommendations are not linked to evidence
A Strong recommendation:

- Direct level I evidence

B Moderate recommendation:

- Direct level II evidence or extrapolated level I evidence

C Weak recommendation

- Direct level III evidence or extrapolated level II evidence

D Consensus recommendation:

- Expert opinion based on very limited evidence
RCT: randomized controlled trial; NR: not reported.

was sought. Canadian recommendations were worded according to published criteria for improving implementability of guidelines ${ }^{17}$ and were voted on using a modified Delphi consensus technique. Each participant registered a vote ranging from 1 (disagree strongly with recommendation) to 10 (agree strongly with recommendation), and disagreements were resolved through discussion and multiple rounds of voting accordingly.

Extended review. Draft recommendations developed by the working group were sent to members of the CRA for review and comment. Feedback from survey respondents $(n=86)$ was used to finalize recommendations and inform supporting text discussions. The present document was prepared in accordance with the principles outlined by the AGREE instrument V1 (www.agreecollaboration.org) and the Conference on Guideline Standardization checklist ${ }^{18}$. These recommendations were then sent for final review by the CRA executive and received official endorsement by the CRA.

\section{RESULTS}

\section{Key to Understanding This Guidance}

Each recommendation is presented with a level of evidence and strength (Table 2) and is accompanied by supporting text that is structured as follows:

Summary of guidelines. A synthesis of recommendations made by international RA guidelines identified from the systematic review.

Recommendation/supporting evidence. Specific source guidelines that were used for adaptation.

Summary of evidence linked to recommendation. A summary of the original evidence presented in source guidelines used for adaptation.

Evidence to recommendation. A discussion of the guideline panel's interpretation of the evidence, clinical experience, and values used to develop the recommendation.

Potential barriers for implementation. Canadian system factors that may influence the applicability of the recommendation.

\section{Overarching Principles in the Care of Persons with RA:}

1. Patients with RA should be cared for by a rheumatologist or by other healthcare professionals trained and experienced in RA diagnosis, clinical assessment, and appropriate prescription of RA drug therapies;

2. Every Canadian with RA should have timely and equal access to appropriate rheumatologic care;

3. Treatment of patients with RA should be based on shared decision-making between patient and physician. This should include provision of appropriate RA education materials to patients and caregivers and clear discussion of the benefits and potential risks of treatment;

4. The development of shared-care models with primary care physicians and/or other allied health professionals trained in musculoskeletal (MSK) conditions could enhance healthcare delivery for patients with RA, particularly given the current shortage of rheumatologists in Canada. Such models include support for timely identification and referral of early arthritis patients, guidance for monitoring disease activity in patients with established disease, and the management of comorbidities;

5. RA healthcare providers should consider opportunities for engaging patients in research both as participants and as potential research partners/consumer representatives to further the knowledge and understanding of RA.

\section{Recommendations}

A summary of these CRA recommendations is presented in Table 3. Algorithms summarizing recommendations for the assessment and treatment of patients with RA are presented in Figure 2 and Figure 3, respectively.

Recommendation 1:

The goal of treatment is remission and when not possible, minimal disease activity (I) while controlling symptoms, halting damage, preventing disability, and improving quality of life (IV). (Level I, IV; Strength A) Summary of guidelines. The search identified 9 clinical practice guidelines (CPG) and 5 consensus statements (CS) that addressed goals of treatment (AGREE rating: Recommend $(\mathrm{R})=7$, Recommend with provisos $\left(\mathrm{R}^{*}\right)=7$ ). Eleven guidelines recommended that the goal should be remission, and when not possible, low disease activity (LDA) ${ }^{19-29}$, and 2 guidelines recommended a goal of minimal disease activity/ LDA $^{30,31}$. Four guidelines specified additional treatment targets including function, joint destruction, and quality of life outcomes $^{20,28,31,32}$.

Recommendation/supporting evidence. EULAR $2010^{26}$ (R), Treat to Target $2010^{25}(\mathrm{R})$, British Society of Rheumatology (BSR) $2009^{30}(\mathrm{R})$, SIGN $2000^{32}$ (R).

$$
\text { Personal non-commercial use only. The Journal of Rheumatology Copyright } @ \text { } \subset \text { 2012. All rights reserved. }
$$


Table 3. Canadian Rheumatology Association (CRA) recommendation for the pharmacological management of RA with traditional and biologic DMARD.

General RA management strategies

1. The goal of treatment is remission and, when not possible, minimal disease activity (I) while controlling symptoms, halting damage, preventing disability, and improving quality of life (IV)

2. The presence of the following poor prognostic features should be assessed at baseline and considered when making treatment decisions: RF positivity, anti-CCP positivity, functional limitation, high number of swollen and tender joints, early erosions, extraarticular features, high ESR or CRP

3. RA care providers should monitor disease activity as frequently as every 1 to 3 months in patients with active RA (I). Patients with well controlled disease and patients in remission can be monitored at longer intervals (IV)

4. Traditional and biologic DMARD therapy should be adjusted every 3-6 months, as long as the goal has not been achieved

5. Radiographs of the hands and feet are recommended as frequently as every 6-12 months in patients with recent-onset disease (II). Radiographs can be performed at longer intervals in patients with established disease (IV)

6. A change in therapy should be considered in patients with radiographic progression despite adequate clinical response

Treatment with glucocorticoids

7. Glucocorticoids (oral, intramuscular, or intraarticular) can be added to DMARD therapy as part of the initial treatment strategy of patients with RA (I), and may be an option for managing flares, as bridge therapy while waiting for DMARD to take effect, or for symptom control if no other options exist (IV). Glucocorticoids should be used in the lowest possible dose and tapered as rapidly as clinically feasible (IV)

Treatment with MTX/DMARD

8. In patients with persistent synovitis, DMARD should be introduced as soon as possible

9. MTX is the preferred DMARD with respect to efficacy and safety and should be the first DMARD used in patients with RA unless contraindicated

10. A complete blood count (II), liver (I) and renal biochemistry (II), and a chest radiograph (II) should be ordered prior to initiating MTX therapy. Screening for hepatitis B and C should be considered (III), and HIV testing is recommended in high-risk patients (IV)

11. Dosing of MTX should be individualized to the patient (IV). MTX should be started oral or parenteral and titrated to a usual maximum dose of $25 \mathrm{mg} /$ week by rapid dose escalation. In patients with an inadequate response or intolerance to oral MTX, parenteral administration should be considered (I)

12. Initial combination therapy with traditional DMARD should be considered, particularly in patients with poor prognostic features, moderate-high disease activity, and in patients with recent-onset disease. Combination therapy should also be considered in patients who have an inadequate response to monotherapy

13. When treating with combination therapy, MTX should be used as the anchor drug unless contraindicated. Combinations not including MTX can be considered on a case-by-case basis

14. Combination therapy with leflunomide and MTX should be used with caution as it is associated with higher toxicity (gastrointestinal and liver) (I) and has no added benefit relative to other DMARD combinations (IV)

Treatment with biologics

15. In patients being considered for biologic therapy, an inadequate response to DMARD is defined as moderate to high disease

I, IV

II

A

B

I, IV

A

I, IV

B

II, IV

B

IV

D

I, IV

activity despite treatment with at least 2 DMARD (including MTX unless contraindicated) in mono or combination therapy after 3 months at target dose

16. Routine laboratory tests (complete blood count, liver and renal biochemistry) and screening for hepatitis B and C (and HIV in high-risk patients) are recommended prior to initiating all biologic therapy. Screening for latent tuberculosis is recommended prior to anti-TNF, abatacept, and tocilizumab. Baseline antinuclear antibody testing could be considered prior to starting anti-TNF

17. MTX coprescription with biologics is recommended for improved efficacy

18. Anti-TNF therapy is recommended for treatment of patients with RA after an inadequate response to DMARD (I). In exceptional circumstances involving patients with DMARD contraindications or high disease activity and poor prognostic factors (particularly early disease), anti-TNF therapy may be an option after failure of DMARD monotherapy or in DMARD naive patients

19. Abatacept is recommended for the treatment of patients with RA after inadequate response to DMARD or anti-TNF therapy

20. Rituximab is recommended for the treatment of patients with RF-positive RA after an inadequate response to DMARD or anti-TNF therapy

21. Patients should not be expected to flare before they are retreated with rituximab (IV). Retreatment can occur as early as 6 months if the patient has had an initial response but has persistent synovitis (II)

22. Tocilizumab is recommended for the treatment of patients with RA after inadequate response to DMARD or anti-TNF therapy

23. In patients who have failed treatment with 1 anti-TNF due to lack of efficacy or toxicity the following options are recommended: switch to another anti-TNF (I, II), switch to another biologic with a different mechanism of action (abatacept, rituximab, tocilizumab) (I), or add MTX (or other DMARD) if anti-TNF was used in monotherapy (II)

24. In patients who have failed treatment with 2 anti-TNF a switch to another biologic with a different mechanism of action (abatacept, rituximab, tocilizumab)) is recommended

25. In the absence of data on therapeutic strategies after failure of abatacept, rituximab, or tocilizumab the following options can be considered: switch to any biologic not previously tried and failed, add or switch to a traditional DMARD not previously tried and failed, or enroll the patient in a clinical trial with a new agent

26. If a patient achieves sustained remission after discontinuation of NSAID and glucocorticoids, a reduction in traditional and biologic DMARD can be attempted with caution as a shared decision between the patient and physician

$\begin{array}{cc}\text { I } & \text { A } \\ \text { I } & \text { A } \\ \text { IV } & \end{array}$

I, IV A

B

A

I, IV A

IV

IV

I A

I A

I A

I A

II, IV C

I A

I, II $\quad$ B

II/IV C

IV D

IV $\mathrm{D}$

RA: rheumatoid arthritis; DMARD: disease-modifying antirheumatic drug; anti-CCP: anti-cyclic citrullinated peptide antibody; ESR: erythrocyte sedimentation rate; CRP: C-reactive protein; HIV: human immunodeficiency virus; MTX: methotrexate; NSAID: nonsteroidal antiinflammatory drug; RF: rheumatoid factor.

Personal non-commercial use only. The Journal of Rheumatology Copyright @) 2012. All rights reserved. 


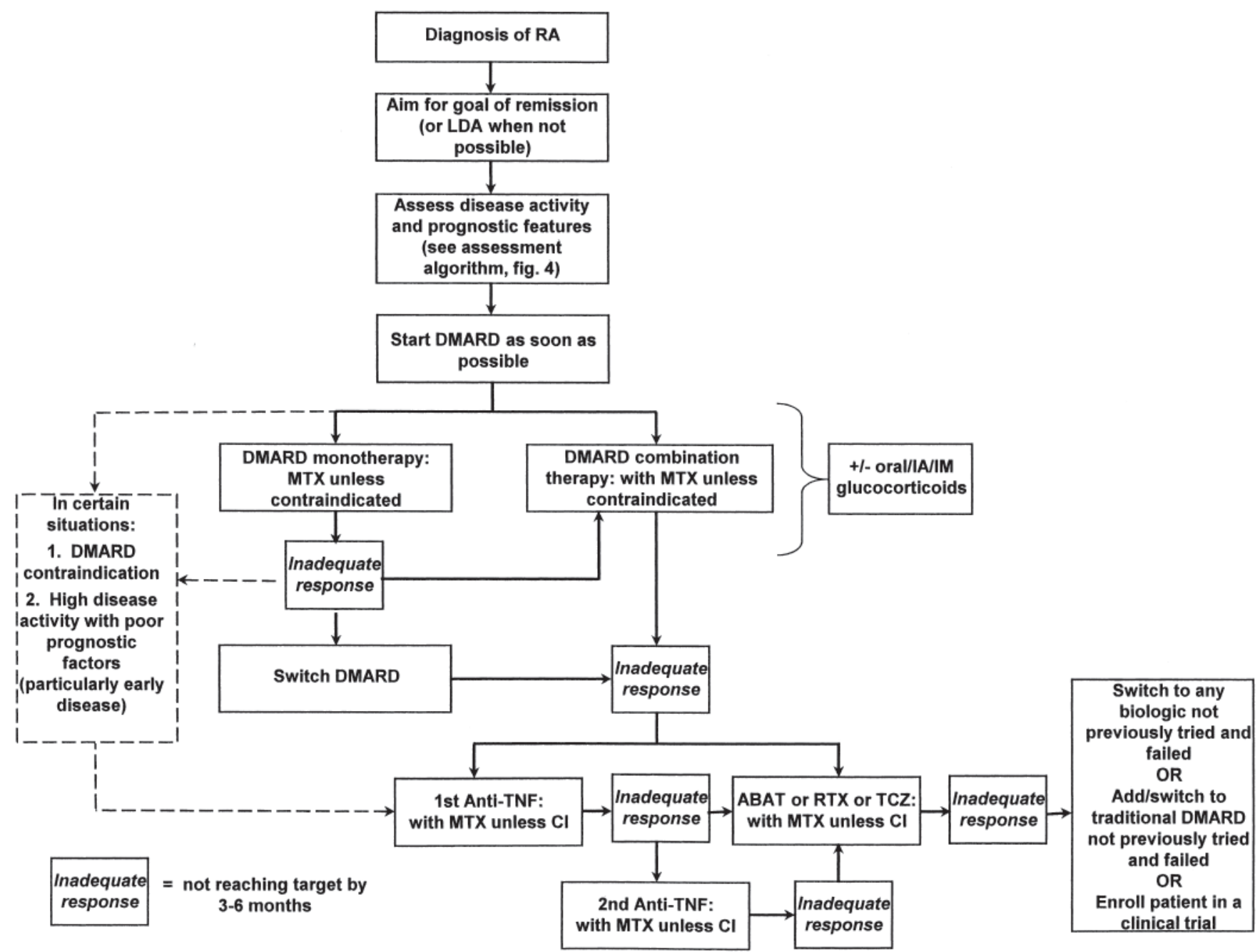

Figure 2. Algorithm based on the Canadian Rheumatology Association (CRA) recommendations for the pharmacological treatment of rheumatoid arthritis (RA) with traditional and biologic disease-modifying antirheumatic drugs (DMARD). LDA: low disease activity; DMARD: disease-modifying antirheumatic drug; CI: contraindicated; IA: intraarticular; IM: intramuscular; MTX: methotrexate; anti-TNF: tumor necrosis factor inhibitor; ABAT: abatacept; RTX: rituximab; TCZ: tocilizumab.

Summary of evidence linked to recommendation. EULAR 2010 guidelines ${ }^{26}$ and the 2010 Treat to Target Taskforce ${ }^{25}$ referred to evidence from RCT and several observational studies showing that patients who attain a state of remission have better structural and functional outcomes than patients who have residual disease activity. The 2010 Treat to Target Taskforce ${ }^{25}$ qualified, however, that no trial has directly compared targeting remission to other treatment strategies; all strategic trials (studies comparing more intensive treatment strategies to usual care) have used LDA as the threshold to escalate therapy. The 2009 BSR guidelines add that there is evidence from observational studies that remission may be a difficult goal in certain patients ${ }^{30} .2000$ Scottish guidelines review observational studies emphasizing additional outcomes including symptom control, preventing disability and joint damage, and improving quality of life $\mathrm{e}^{32}$.

Evidence to recommendation. The guideline panel agreed that remission should be the target but may be difficult in certain patients, particularly those with long-standing RA. Several composite measures of disease activity have been developed and validated in patients with RA. The panel recognizes, however, that composite measures may have limitations in daily routine practice. The panel therefore provides a reference guide of published disease activity criteria/thresholds (Table 4) and agreed that the choice of measure should be left to the discretion of the rheumatologist. Further, the use of patientcentered outcomes (pain, function, quality of life) in addition to disease activity was also emphasized.

Barriers to implementation. None.

Recommendation 2:

The presence of the following poor prognostic features should be assessed at baseline and considered when making treatment decisions: rheumatoid factor (RF) positivity, anticyclic citrullinated peptide antibodies (anti-CCP) positivity, functional limitation, high number 
Table 4. Reference guide of rheumatoid arthritis disease activity measures ${ }^{36,94,95,96,97}$

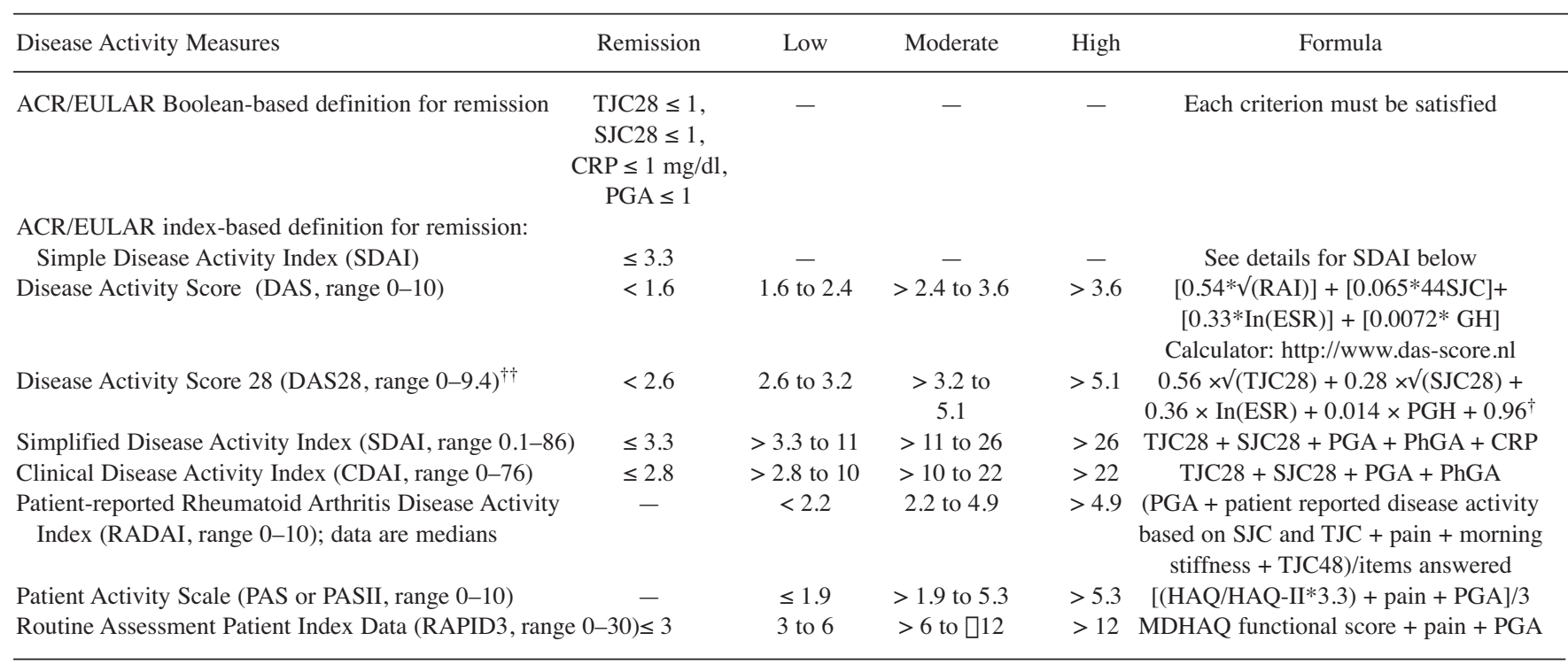

$\dagger$ Calculator: http://www.das-score.nl. ${ }^{\dagger}$ Alternative DAS/DAS28 formulas based on the use of CRP rather than ESR are available from http://www.das-score.nl. Other cut points for the DAS28 have also been proposed (remission $\leq 2.4$, low activity $\leq 3.6$, high activity $>5.5)^{5}$. DAS: Disease Activity Score based on 44 joint counts; RAI: Ritchie Articular Index; DAS28: Disease Activity Score based on 28-joint counts; TJC28: tender joint count based on 28-joint count; SJC28: swollen joint count based on 28-joint count; ESR: erythrocyte sedimentation rate; PGH: patient global assessment of health [visual analog scale (VAS) 0-100 mm]; PGA: patient global assessment of disease activity (VAS 0-10 cm); PhGA: physician global assessment of disease activity (VAS 0-10 cm); CRP: C-reactive protein, mg/l; TJC48: tender joint count based on 48-joint count; HAQDI: Health Assessment Questionnaire Disability Index (0-3); HAQ-II: modified HAQ (0-3); MDHAQ: Multidimensional Health Assessment Questionnaire (0-10).

of swollen and tender joints, early erosions, extraarticular features, high erythrocyte sedimentation rate (ESR) or C-reactive protein (CRP). (Level II; Strength B)

Summary of guidelines. The search identified 7 CPG that addressed prognostic factors (AGREE rating: $R=5, R^{*}=2$ ). All 7 guidelines identified the following baseline poor prognostic factors: RF and/or anti-CCP positivity, high ESR or CRP levels, early radiographic erosions, and high swollen and tender joint counts $22,23,26,33,34,35,36$. In addition, 3 guidelines included baseline functional disability ${ }^{23,34,36}, 2$ included extraarticular disease ${ }^{23,34}, 2$ included demographic characteristics and disease duration ${ }^{22,23}, 2$ included genetic markers $^{22,34}$, and 1 included grip strength ${ }^{23}$.

Recommendation/supporting evidence. $2009 \mathrm{NICE}^{23}$ (R), EULAR $2007^{33}\left(\mathrm{R}^{*}\right)$.

Summary of evidence linked to recommendation. The 2009 NICE guidelines ${ }^{23}$ and 2007 EULAR guidelines ${ }^{33}$ review observational studies and indirect evidence from RCT supporting the prognostic value of each factor for clinical and radiographic outcomes in patients with recent-onset RA. 2010 EULAR $^{26}$ guidelines state that the titer of anti-CCP and RF is important, but no threshold levels for RF/anti-CCP titers or ESR/CRP values were listed in any of the guidelines. 2009 NICE guidelines ${ }^{23}$ also added that there is some evidence that patients who are both RF and anti-CCP positive may have a worse prognosis than patients positive for either antibody alone ${ }^{37}$.
Evidence to recommendation. The baseline poor prognostic factors listed in the recommendation are supported by evidence and were agreed to be the most relevant and practical indicators for making treatment decisions. The panel also acknowledged that additional factors influencing prognosis (e.g., comorbidities, sociodemographic, psychosocial, and genetic factors) may also affect treatment decisions.

Barriers to implementation. Anti-CCP testing is not uniformly reimbursed by government-funded healthcare across Canada.

Recommendation 3:

RA care providers should monitor disease activity as frequently as every 1 to 3 months in patients with active RA (I). Patients with well controlled disease and patients in remission can be monitored at longer intervals (IV). (Level I, IV; Strength A)

Summary of guidelines. The search identified 12 CPG and 3 CS that addressed frequency of monitoring disease activity (AGREE rating: $R=7, R^{*}=7$, WNR $=1$ ). Seven general $R A$ management guidelines recommended assessments every 1-3 months in active disease $21,23,25,26,27,30,38$, with 5 specifying longer intervals for patients with well controlled disease $^{25,27,30,38,39}$. One guideline recommended shared-care for patients with well controlled disease by a general practitioner every 3-6 months and by a specialist every 6-12 months. 
Frequency of

Assessment
Pre-treatment

Investigations

Baseline:

$\mathrm{CBC}$, liver and renal biochemistry, RF, anti-CCP, ESR, CRP, radiographs hands/feet

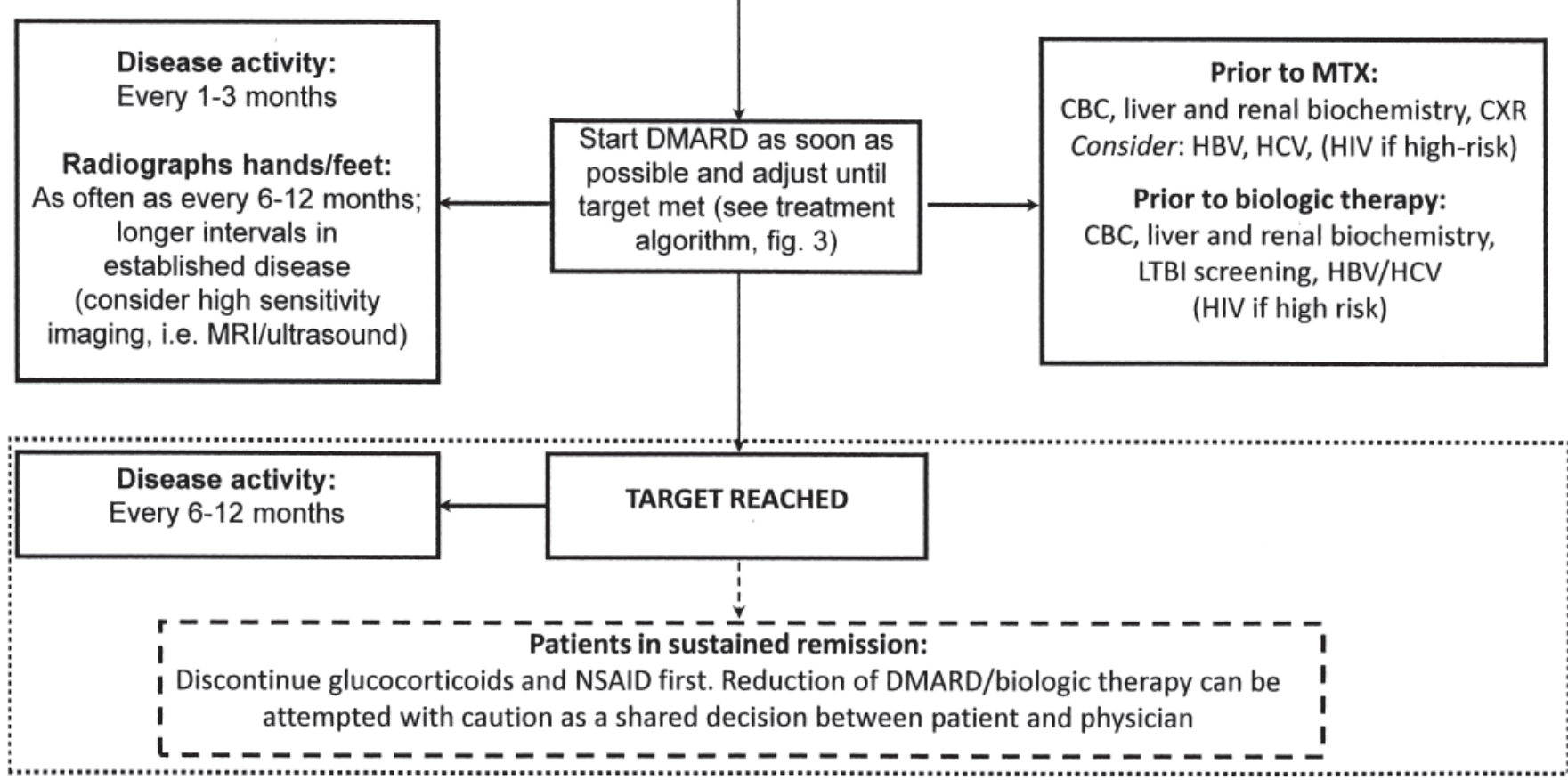

Figure 3. Algorithm based on the Canadian Rheumatology Association recommendations for the assessment of patients with rheumatoid arthritis (RA). DMARD: disease-modifying antirheumatic drug; NSAID: nonsteroidal antiinflammatory drugs; MRI: magnetic resonance imaging; CBC: complete blood cell count; RF: rheumatoid factor; anti-CCP: anticyclic citrullinated peptide antibodies; ESR: erythrocyte sedimentation rate; CRP: C-reactive protein; CXR: chest radiograph; LTBI: latent tuberculosis infection; HBV/HCV: hepatitis B/C.

Seven guidelines recommended assessments at least every 3-6 months for patients taking biologics without providing a distinction based on RA disease status $24,35,39,40,41,42,43$.

Recommendation/supporting evidence. EULAR $2010^{26}(\mathrm{R})$, Smolen $2010^{25}$ (R).

Summary of evidence linked to recommendation. A systematic review of trials on strategy-driven treatment approaches in RA performed to inform the EULAR 2010 guidelines ${ }^{44}$ concluded that intensive treatment strategies produce a better clinical outcome, improved physical function, and less structural damage than less intensive strategies. The $13 \mathrm{RCT}$ that compared target-driven treatment approaches to usual care used followup intervals of between 1 and 4 months in the treatment group. Two of these $\mathrm{RCT}^{45,46}$ showed improved outcomes with monthly assessments and treatment adjustment to a target of LDA compared to assessments every 3 months with treatment adjustment left to the discretion of the rheuma- tologist. An additional trial showed benefit with monthly assessments and a target-driven treatment approach to routine care with no specified interval for assessment ${ }^{47}$. The 2010 Treat to Target Taskforce ${ }^{25}$ also provided evidence from observational studies that radiographic progression can be seen in patients with high disease activity in as little as a few weeks. For patients with established disease, a French guideline ${ }^{38}$ provided evidence from prospective cohorts showing that patient-initiated followup was equivalent to physicianscheduled appointments over 6 years ${ }^{48,49}$.

Evidence to recommendation. The panel agreed that frequent assessments with appropriate treatment adjustment in patients with active RA are associated with improved outcomes. The panel also recognized that while 1 month is too short to see a maximal therapeutic effect of DMARD therapy, modifying the treatment approach (dosage change and/or adding shortterm glucocorticoid) may be appropriate within this time-

$$
\text { Personal non-commercial use only. The Journal of Rheumatology Copyright @ } 2012 \text {. All rights reserved. }
$$


frame. Longer assessment intervals were agreed to be appropriate in patients with well controlled disease, who should be instructed to consult their rheumatologist in case of flare/worsening. Shared-care models with other healthcare providers trained in the assessment of patients with RA could aid in the optimal monitoring of disease activity and adjustment of therapy.

Barriers to implementation. There is a shortage of rheumatologists and other healthcare providers trained in the assessment of patients with RA that could participate in shared-care models in Canada. Shared-care models are not currently widely available in Canada.

Recommendation 4:

Traditional and biologic DMARD therapy should be adjusted every 3-6 months, as long as the goal has not been achieved (Level I, IV; Strength B).

Summary of guidelines. One CPG and 1 CS provided general strategies for adjusting traditional and biologic DMARD (AGREE rating: $\mathrm{R}=2$ ). Both recommended adjusting therapy until the treatment target is reached. EULAR 2010 guidelines $^{26}$ suggested adjusting therapy every 1-3 months, although major adjustments in therapy (switching or adding a DMARD or biologic) should occur every 3-6 months, as outlined by their provided algorithm. The Treat to Target Taskforce ${ }^{25}$ recommended an adjustment in therapy at least every 3 months.

Recommendation/supporting evidence. EULAR $2010^{26}$ (R).

Summary of evidence linked to recommendation. EULAR 2010 guidelines ${ }^{26}$ referred to strategic trials showing that frequent therapy adjustment based on reaching a target response is associated with better outcomes. Timing of adjustment, however, should also consider the pharmacokinetics of the medications used. 2008 BSR guidelines ${ }^{50}$ suggested that on average 3 months is sufficient to assess the therapeutic effect for the majority of DMARD (except intramuscular gold: 4-6 months $\mathrm{s}^{47}$ and hydroxychloroquine: 4 months ${ }^{29}$ ). French guidelines suggest that a response to anti-TNF can be assessed on average after 3 months ${ }^{39}$, rituximab and abatacept after 4 months ${ }^{41,42}$, and tocilizumab after 3-6 months ${ }^{24}$.

Evidence to recommendation. The panel considered the evidence from strategy-driven RCT and agreed that 3-6 months balances minimizing missed opportunities for timely adjustment with the time needed to observe a therapeutic effect of most treatments. Adjustment in the context of this recommendation refers to changing DMARD strategy (adding or switching agent). Modifying the treatment approach (dosage change and/or adding short-term steroid) can occur more frequently based on the patient's clinical status (Recommendation 3).

Barriers to implementation. There is a shortage of rheumatologists and other healthcare providers trained in the assessment of patients with RA in Canada.
Recommendation 5:

Radiographs of the hands and feet are recommended as frequently as every 6-12 months in patients with recent-onset disease (II). Radiographs can be performed at longer intervals in patients with established disease (IV). (Level II, IV; Strength B)

Summary of guidelines. The search identified 6 CPG and 3 CS that addressed this question (AGREE rating: $\mathrm{R}=2, \mathrm{R}^{*}=7$ ). Two guidelines recommended radiographs every 6-12 months for the first few years of disease ${ }^{22,33}$, and 7 guidelines recommended annual radiographs without further specification $^{20,24,25,27,31,39,42}$.

Recommendation/supporting evidence. EULAR $2007^{33}\left(\mathrm{R}^{*}\right)$.

Summary of evidence linked to recommendation. 2007 EULAR $^{33}$ guidelines reported that the greatest change in radiographic progression occurs within the first 2 years of disease onset and reference observational studies showing that structural progression can be reliably assessed in as little as 6 months using a formal scoring system (progression defined as $\geq 4$ Sharp points).

Evidence to recommendation. The panel agreed that radiographs should be ordered more frequently in recent-onset disease than in patients with established disease, particularly in patients with poor prognostic factors. The panel also recognized that the timing interval was controversial and depends on the sensitivity to change of the method used for radiograph interpretation and the potential influence of the results on the patient's therapy. Given that formal radiographic scoring is not performed in routine practice, radiographs every 6 months may not be necessary in all patients. However, in certain cases where there is concern that the patient is developing erosions that were not present initially, repeating radiographs early may be warranted to help guide a change in therapy. Other imaging technologies (ultrasound and magnetic resonance imaging) can also be considered.

Barriers to implementation. Limitations in the reliability of interpreting serial radiographs.

\section{Recommendation 6:}

A change in therapy should be considered in patients with radiographic progression despite an adequate clinical response. (Level IV; Strength D)

Summary of guidelines. The search identified $3 \mathrm{CPG}$ and $2 \mathrm{CS}$ that addressed this question (AGREE rating: $\mathrm{R}=1, \mathrm{R}^{*}=4$ ). Four guidelines ${ }^{27,39,51,52}$ suggested a change in therapy in patients with radiographic progression despite an adequate clinical response, while one guideline ${ }^{26}$ cautioned that lag periods in radiographic progression should be taken into account.

Recommendation/supporting evidence. EULAR $2010^{26}$ (R), FSR $2007^{39}\left(\mathrm{R}^{*}\right)$.

Summary of evidence linked to recommendation. EULAR

Personal non-commercial use only. The Journal of Rheumatology Copyright @ 2012. All rights reserved. 
2010 guidelines ${ }^{26}$ and 2007 French guidelines ${ }^{39}$ recommended that radiographic progression should be considered when adjusting therapy, especially if joint damage appears to progress markedly despite the achievement of the desired treatment target, but did not provide citable evidence. EULAR 2010 guidelines, however, also referred to indirect evidence from an RCT suggesting that radiographic change lags the achievement of clinical remission ${ }^{53}$. Evidence is lacking on the efficacy of adjusting versus maintaining therapy in patients who have radiographic progression despite achieving a clinical response.

Evidence to recommendation. The panel recognized that radiographic progression is an important factor in the decision to adjust therapy, but that treatment decisions should take into account progression within the complete clinical context of the patient.

Barriers to implementation. Limitations in the reliability of interpreting serial radiographs.

Recommendation 7:

Glucocorticoids (GC; oral, intramuscular, or intraarticular) can be added to DMARD therapy as part of the initial treatment strategy of patients with RA (I), and may be an option for managing flares, as bridge therapy while waiting for DMARD to take effect, or for symptom control if no other options exist (IV). GC should be used in the lowest possible dose and tapered as rapidly as clinically feasible (IV). (Level I, IV; Strength A/D)

Summary of guidelines. The search identified $8 \mathrm{CPG}$ and $4 \mathrm{CS}$ that addressed the use of GC in RA (AGREE rating: $\mathrm{R}=5$, $\mathrm{R}^{*}$ $=7$ ). Five guidelines recommended using short-term low-dose GC in patients with early $\mathrm{RA}^{22,23,26,34,54}, 3$ recommended using GC for managing flares ${ }^{20,23,34}, 3$ as bridge therapy while waiting for DMARD to take effect ${ }^{20,22,54}$, and 3 for other situations ${ }^{28,31,52}$. Only 2 guidelines recommended against using GC or stated that their use is controversial ${ }^{29,32}$. Recommendation/supporting evidence. EULAR $2010^{26}$ (R), $2009 \mathrm{NICE}^{23}(\mathrm{R})$.

Summary of evidence linked to recommendation. The strongest evidence supporting a role of GC in patients with RA is as part of initial short-term combination therapy with other DMARD in patients with early RA. A systematic review of RCT informing the EULAR 2010 guidelines ${ }^{55}$ showed benefit of short-term treatment with GC for symptom control and inhibiting radiographic progression when added to DMARD monotherapy or DMARD combination therapy in patients with early RA, but found insufficient evidence to recommend an optimal tapering strategy. For the use of GC in other situations, the 2009 NICE guidelines ${ }^{23}$ highlighted a discordance between strong anecdotal evidence of the benefit of using GC as bridge therapy and for managing flares, and the paucity of research studies. EULAR 2007 glucocorticoid guidelines ${ }^{56}$ state that patients treated with GC should be monitored closely and that the risk of adverse events will depend on the dose and duration of GC used.

Evidence to recommendation. The panel agreed with the body of evidence supporting short-term use of GC in the initial management of patients with RA and acknowledged the anecdotal evidence regarding efficacy of GC for managing flares and as bridge therapy. The panel was concerned with the potential for toxicity associated with use of GC, and while they agreed GC should be used in low doses and tapered rapidly, an optimal tapering strategy could not be recommended. When choosing a route of administration, intramuscular or intraarticular steroids allow more control over the total cumulative dose and may be preferred in certain situations. Intraarticular steroids were agreed to be particularly useful for controlling residual synovitis if a few swollen joints remain, as they avoid systemic toxicity.

Barriers to implementation. None.

Recommendation 8:

In patients with persistent synovitis, DMARD should be introduced as soon as possible. (Level I; Strength A) Summary of guidelines. The search identified 5 CPG and 5 CS that addressed starting DMARD therapy (AGREE rating: $\mathrm{R}=$ $4, R^{*}=6$ ). Five guidelines recommended starting DMARD immediately/as soon as possible once the diagnosis is made $^{21,22,26,27,29}$ and 5 recommended starting within 2-4 months of persistent symptoms of RA $20,23,31,32,57$.

Recommendation/supporting evidence. EULAR $2010^{26}(\mathrm{R})$, Spanish Society of Rheumatology (SER) $2010^{27}\left(\mathrm{R}^{*}\right)$.

Summary of evidence linked to recommendation. EULAR 2010 guidelines $^{26}$ and 2010 Spanish guidelines ${ }^{27}$ referred to evidence from RCT and observational studies showing that delaying DMARD therapy results in worse clinical, function$\mathrm{al}$, and radiographic outcomes. EULAR 2010 guidelines ${ }^{26}$ further suggested that DMARD therapy may be initiated in suspected cases of RA and cited recently published 2010 ACR/EULAR RA classification criteria ${ }^{9}$, which may assist in early diagnosis.

Evidence to recommendation. The panel agreed that there is conclusive evidence supporting early treatment with DMARD in patients with RA. The diagnosis of early RA can be difficult, and therefore the recommendation refers to patients with persistent synovitis, including patients with a strong suspicion of RA, but who do not meet full classification criteria.

Barriers to implementation. Lags in appropriate identification and referral of patients with early RA.

Recommendation 9:

Methotrexate is the preferred DMARD with respect to efficacy and safety and should be the first DMARD used in patients with RA unless contraindicated. (Level I; Strength A)

$$
\text { Personal non-commercial use only. The Journal of Rheumatology Copyright @ } 2012 \text {. All rights reserved. }
$$


Summary of guidelines. The search identified 7 CPG and 6 CS that addressed which DMARD to use first (AGREE rating: $\mathrm{R}=6, \mathrm{R}^{*}=7$ ). Seven guidelines recommended starting with MTX as the first DMARD $2,20,23,26,28,31,58,2$ recommended starting with either methotrexate (MTX) or sulfasalazine (SSZ) $)^{22,32}$, and 3 recommended starting with either MTX or leflunomide (LEF) $27,29,59$. Two guidelines recommended that hydroxychloroquine (HCQ) or SSZ could be started first in patients with mild disease ${ }^{22,32}$. One guideline provided an algorithm to guide the choice of initial therapy ${ }^{36}$.

Recommendation/supporting evidence. EULAR $2010^{26}(\mathrm{R})$.

Summary of evidence linked to recommendation. 2010 EULAR guidelines ${ }^{26}$ provided evidence from RCT and observational studies that MTX is effective in DMARD-naive patients with early moderate to severe RA and that no other traditional DMARD or anti-TNF monotherapies have been shown to be superior to MTX in terms of clinical efficacy. They also referred to a systematic review that supports the beneficial longterm safety profile of MTX ${ }^{60} .2007$ Spanish guidelines ${ }^{54}$ referred to observational evidence that MTX has a lower rate of treatment dropout in the medium to long term as compared to other DMARD.

Evidence to recommendation. The panel agreed that there is sufficient evidence to support MTX as the preferred DMARD in patients with RA based on its efficacy and safety profile. The panel recognized that other DMARD have also been proven to be effective (e.g., LEF, SSZ, HCQ, etc.) and may be considered in certain situations. Examples include patients with contraindications to MTX, patients with mild disease and/or in situations in which MTX use may not be desirable (e.g., a young woman who may become pregnant).

Barriers to implementation. None.

Recommendation 10:

A complete blood cell count (CBC) (II), liver (I) and renal biochemistry (II), and a chest radiograph (II) should be ordered prior to initiating methotrexate (MTX) therapy. Screening for hepatitis B/C should be considered (III), and HIV testing is recommended in high-risk patients (IV). (Level I-IV; Strength B/D)

Summary of guidelines. The search identified $3 \mathrm{CPG}$ and $3 \mathrm{CS}$ addressing investigations for MTX (AGREE rating: $\mathrm{R}=2, \mathrm{R}^{*}$ $=4)$. Five guidelines recommended CBC, liver transaminases, kidney biochemistry, and a recent chest radio$\operatorname{graph}^{20,50,54,61,62}$, and 1 suggested all except chest radio$\operatorname{graph}^{36}$. In addition to the factors above, 4 guidelines also recommended serum albumin 50,54,61,62 and 4 recommended hepatitis $\mathrm{B} / \mathrm{C}$ serology $20,36,61,62$ (2 recommended these in all patients ${ }^{61,62}$, and 2 only in patients with risk factors ${ }^{20,36}$ ). Two guidelines recommended pulmonary function tests in select patients $^{50,61}, 2$ recommended a liver biopsy in patients with preexisting liver disease ${ }^{54,61}$, and 1 suggested considering ordering an HIV test, fasting glucose, fasting lipids and pregnancy test ${ }^{62}$.

Recommendation/supporting evidence. Visser $2009^{62}\left(\mathrm{R}^{*}\right)$, Pavy $2006^{61}\left(\mathrm{R}^{*}\right)$.

Summary of evidence linked to recommendation. Recommended investigations were based on systematic reviews performed as part of 2 international consensus statements ${ }^{61,62}$. Ordering liver and renal biochemistry and a chest radiograph is based on observational studies showing that renal failure, decreased albumin, elevated transaminases, and baseline chest radiographic abnormalities are associated with increased toxicity from MTX. Ordering a CBC is based on the increased risk of cytopenias in patients treated with MTX. Ordering hepatitis B/C serology and HIV testing in high-risk patients is based on case reports of hepatitis $\mathrm{B} / \mathrm{C}$ reactivation while on MTX and expert opinion, respectively.

Evidence to recommendation. The panel chose the specified investigations listed in the recommendation based on the available evidence and clinical experience. Hepatitis B/C and HIV testing was supported by weak evidence and was therefore worded as "should be considered."

Barriers to implementation. None.

Recommendation 11:

Dosing of methotrexate (MTX) should be individualized to the patient (IV). MTX should be started oral or parenteral and titrated to a usual maximum dose of 25 mg per week by rapid dose escalation. In patients with an inadequate response or intolerance to oral MTX, parenteral administration should be considered (I). (Level I, IV; Strength A)

Summary of guidelines. The search identified 3 CPG and 4 CS that addressed dosing of MTX (AGREE rating: $\mathrm{R}=1, \mathrm{R}^{*}=$ 6). Six guidelines recommended a starting dose of 5-10 mg, with a maximum dose of 20-25 mg per week $2,27,31,34,50,61$, and 1 recommended a starting dose of $10-15 \mathrm{mg}$ with a maximum dose of $20-30 \mathrm{mg}$ per week ${ }^{62}$. Five guidelines commented on the schedule for dose escalation; 2 recommended escalating by $2.5-5 \mathrm{mg}$ every $2-6$ weeks ${ }^{27,50} ; 1$ recommended escalating by $5 \mathrm{mg}$ every $2-4$ weeks $^{62} ; 1$ recommended escalating every 6 weeks without specifying the dose increment $^{61}$; and 1 simply recommended rapid dose escalation ${ }^{22}$. All guidelines recommend starting with oral (po) MTX and switching to parenteral if there is intolerance or lack of efficacy, poor compliance ${ }^{61}$, or dose $\geq 15 \mathrm{mg}^{31}$.

Recommendation/supporting evidence. Visser $2009^{62}\left(\mathrm{R}^{*}\right)$.

Summary of evidence linked to recommendation. Visser $2009^{62}$ referred to evidence from RCT supporting higher starting doses of MTX and rapid dose escalation ${ }^{46,63,64}$. Two trials compared a higher versus lower starting dose of MTX in patients with RA: $12.5-20 \mathrm{mg} / \mathrm{wk}$ vs $5-10 \mathrm{mg} / \mathrm{wk}^{63}$ and 25 $\mathrm{mg} / \mathrm{wk}$ vs $15 \mathrm{mg} / \mathrm{wk}^{64}$. Both trials showed improved efficacy; 1 trial showed no difference in toxicity ${ }^{63}$, and the other a trend

Personal non-commercial use only. The Journal of Rheumatology Copyright @ 2012. All rights reserved. 
toward more gastrointestinal (GI) toxicity ${ }^{64}$. Visser 2009 also referred to evidence from retrospective studies that suggested better efficacy and less GI toxicity with parenteral versus oral MTX, potentially explained by the higher bioavailability of subcutaneous (sc) MTX. A recent post-hoc analysis from an $\mathrm{RCT}^{65}$ also showed that over half the patients that were switched from oral to sc MTX after intolerance or inefficacy showed clinical improvement.

Evidence to recommendation. The panel agreed with starting with higher doses of MTX (e.g., $15 \mathrm{mg}$ ) with rapid dose escalation, including in certain situations starting directly at target dose. No specific schedule was recommended, as the optimal schedule for dose escalation was acknowledged to depend on the clinical context of the patient. Initial therapy with sc MTX (e.g., $>15 \mathrm{mg}$ ) or switching to sc administration after failure of oral MTX due to intolerance or inefficacy were recognized as appropriate options. In the latter case, other alternatives such as adding or switching DMARD could also be considered.

\section{Barriers to implementation. None.}

\section{Recommendation 12:}

Initial combination therapy with traditional DMARD should be considered, particularly in patients with poor prognostic features, moderate-high disease activity, and in patients with recent-onset disease. Combination therapy should also be considered in patients who have an inadequate response to monotherapy. (Level I; Strength B)

Summary of guidelines. The search identified 5 CPG and 3 CS that addressed when to use traditional DMARD combination therapy (AGREE rating: $\mathrm{R}=4, \mathrm{R}^{*}=3$, WNR $=1$ ). Two guidelines recommended starting with combination DMARD in all patients with early active $\mathrm{RA}^{23,66}$; 2 recommended starting with combination therapy in certain situations including high disease activity and in the presence of poor prognostic factors, or after failure of DMARD monotherapy ${ }^{20,36} ; 3$ recommended combination therapy after failure of DMARD monotherapy $29,50,58$; and one guideline recommended the use of DMARD monotherapy over combination therapy ${ }^{26}$.

Recommendation/supporting evidence. ACR $2008^{36}$ (R); 2009 $\mathrm{NICE}^{23}$ (R); EULAR $2010^{26}$ (R).

Summary of evidence linked to recommendation. 2008 ACR guidelines $^{36}$ reviewed the RCT evidence showing efficacy of various specific DMARD combinations in different clinical situations, such as in patients with moderate-high disease activity and poor prognostic factors. 2009 NICE guidelines ${ }^{23}$ performed a systematic review of RCT and observational studies and found that several combination therapies (most of which included GC) were superior to monotherapy for both clinical and radiographic outcomes, and that combination therapy was also very likely to be cost-effective. EULAR 2010 guidelines ${ }^{26}$ performed a systematic review of $\mathrm{RCT}^{67}$ and noted that trials comparing combination therapy to monotherapy often did not include an appropriate control arm (e.g., switching to another DMARD monotherapy) and commonly included higher rates of GC use in the combination arm. Evidence to recommendation. The panel recognized that different highly rated guidelines came to different conclusions regarding the same literature. The panel agreed that while the body of evidence supporting combination therapy has some limitations, there is sufficient evidence to consider the use of specific DMARD combinations as initial therapy and/or after inadequate response to monotherapy, particularly in the clinical situations highlighted in the recommendation.

Barriers to implementation. None.

Recommendation 13:

When treating with combination therapy, methotrexate (MTX) should be used as the anchor drug unless contraindicated. Combinations not including MTX can be considered on a case-by-case basis. (Level I; Strength A)

Summary of guidelines. The search identified 4 CPG and 2 CS that addressed which combination therapies should be used (AGREE rating: $\mathrm{R}=2, \mathrm{R}^{*}=3, \mathrm{WNR}=1$ ). Two guidelines recommended MTX as the anchor drug but did not provide details for specific combinations ${ }^{23,33}$; 4 guidelines recommended specific combination regimens with most including

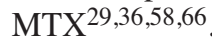

Recommendation/supporting evidence. $2009 \mathrm{NICE}^{23}$ (R), ACR $2008^{36}$ (R).

Summary of evidence linked to recommendation. 2009 $\mathrm{NICE}^{23}$ and ACR $2008^{36}$ provided detailed discussions on the evidence for combination therapy in RA. In most trials, MTX was included as part of the combination therapy, with many individual trials showing increased efficacy for combination therapy over monotherapy. Combination therapies with proven efficacy in at least one RCT include: MTX + sulfasalazine (SSZ), MTX + hydroxychloroquine (HCQ), MTX + HCQ + SSZ, MTX + leflunomide (LEF) (see Recommendation 14 for detailed discussion), MTX + azathioprine (AZA), MTX + cyclosporin A (CsA), MTX + intramuscular (IM) gold, IM gold + HCQ, LEF + SSZ, HCQ + SSZ, CsA + LEF. Detailed descriptions of trials are provided in 2009 $\mathrm{NICE}^{23}$, ACR 2008 36 , and Katchamart $2009^{68}$.

Evidence to recommendation. After reviewing the evidence, the panel agreed that there was sufficient evidence to support the use of MTX as the anchor drug when using combination therapy, although other DMARD combinations may also be considered. Several different combination therapies have been shown to be effective in the treatment of RA, but direct comparative effectiveness data of the different combinations are lacking. The panel therefore agreed it was appropriate to provide a list of combinations supported by evidence and the choice of combination should be left to the discretion of the rheumatologist as a shared decision with the patient, based on individual patient circumstances.

Personal non-commercial use only. The Journal of Rheumatology Copyright @ 2012 . All rights reserved. 
Barriers to implementation. The choice of combination therapy may be influenced by provincial formulary guidelines for accessing a biologic.

Recommendation 14:

Combination therapy with leflunomide (LEF) and methotrexate (MTX) should be used with caution as it is associated with higher toxicity (GI and liver) (I) and has no added benefit relative to other DMARD combinations (IV). (Level I, IV; Strength A)

Summary of guidelines. The search identified $1 \mathrm{CPG}$ and 5 CS that addressed the use of combination therapy with MTX + LEF (AGREE rating: $\mathrm{R}=1, \mathrm{R}^{*}=5$ ). All guidelines stated that combination therapy with MTX + LEF is effective in RA patients with high disease activity. Three guidelines, however, also highlighted that the treatment is associated with increased toxicity and should be used with caution or careful monitoring 2,31,62 .

Recommendation/supporting evidence. Visser $2009^{62}\left(R^{*}\right)$, ACR $2008^{36}$ (R).

Summary of evidence linked to recommendation. Visser $2009^{62}$ and ACR $2008^{36}$ referred to evidence from an RCT ${ }^{69}$ showing better efficacy of combination therapy with leflunomide (LEF) + methotrexate (MTX) compared to MTX + placebo in MTX inadequate responders (MTX-IR) with high disease activity. In the same trial, alanine aminotransferase (ALT) levels were abnormal ( $>1.2$ times upper limit of normal) in $28 / 130(31.5 \%)$ patients in the combination arm versus $6 / 133(6.8 \%)$ in the control arm, although in the majority of patients these normalized without need for a change in dose $^{69}$. A US Food and Drug Administration black-box warning for LEF and risk of severe liver injury was issued July 13, 2010, based on postmarketing surveillance results of 49 cases of severe liver injury including 14 cases of fatal liver failure (46/49 patients were taking concomitant hepatotoxic medications including MTX) $)^{70}$.

Evidence to recommendation. The panel recognized that there is evidence from RCT supporting the efficacy of MTX + LEF in patients with high disease activity with an inadequate response to MTX and that many patients have been successfully treated with this combination without serious adverse events. The panel considered, however, that in general, other combination therapies of proven efficacy would be preferred over LEF + MTX due to increased GI and hepatotoxicity. The panel also recognized that LEF combination therapy is typically considered after an inadequate response to MTX, and that in this situation it is not desirable to withdraw MTX to treat with LEF as this may result in worsening of disease control. If LEF + MTX is used, liver enzymes should be monitored monthly and dose reduction of LEF (to $10 \mathrm{mg}$ ), or MTX should be considered. Similarly, clinicians should exercise caution when combining LEF with other drugs that have the potential to cause liver injury.

Barriers to implementation. Several Canadian provincial for- mularies require patients to fail LEF or combination therapy of MTX + LEF to access a biologic.

Recommendation 15:

In patients being considered for biologic therapy, an inadequate response to DMARD (DMARD-IR) is defined as moderate to high disease activity despite treatment with at least 2 DMARD [including methotrexate (MTX) unless contraindicated] in mono or combination therapy after 3 months at target dose. (Level IV; Strength D)

Summary of guidelines. The search identified $10 \mathrm{CPG}$ and 7 CS that addressed a DMARD-IR (AGREE rating: $\mathrm{R}=3, \mathrm{R}^{*}=$ 14). The number of DMARD recommended to have been tried

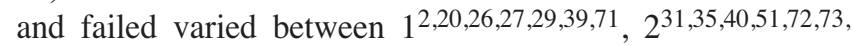
74,75 , and $3^{34}$, with 1 guideline not specifying a number ${ }^{19}$. Recommendations regarding an appropriate duration of a DMARD trial ranged from 3 months ${ }^{19,20,29,39,51,71,74}$ to 6 months ${ }^{31,34,35,40,72,73}$ with 4 not specifying. Almost all guidelines mandated MTX to be a part of the initial DMARD trial unless contraindicated.

Recommendation/supporting evidence. $2009 \mathrm{NICE}^{23}$ (R).

Summary of evidence linked to recommendation. Recommendations from available guidelines were based on expert opinion. 2009 NICE guidelines performed a systematic review of RCT and cost-effectiveness studies to inform their recommendation and found insufficient evidence to conclude whether patients failing initial DMARD therapy should receive another DMARD or proceed directly to biologic therapy.

Evidence to recommendation. The present recommendation was developed based on expert opinion taking into account the Canadian practice setting. Biologics, while proven effective in DMARD inadequate responders (DMARD-IR) and DMARD-naive patients (see Recommendations 19, 20, 22), are associated with higher costs and potential risks for toxicity. Prior treatment with 2 DMARD in mono or combination therapy was chosen to balance the potential opportunity for a response to DMARD therapy with early initiation of a biologic that may be necessary to reach the treatment target. Three months at target dose was agreed to be a sufficient period to observe a therapeutic effect for most DMARD while minimizing delays in treatment adjustment.

Barriers to implementation. Although all Canadian provincial formularies currently require failure of at least 2 DMARD prior to accessing a biologic, many also require failure of an adequate trial of combination therapy (commonly defined as 2-3 months).

Recommendation 16:

Routine laboratory tests (complete blood count, liver and renal biochemistry) and screening for hepatitis B and C (and HIV in high-risk patients) are recommended prior to initiating all biologic therapy. Screening for

Personal non-commercial use only. The Journal of Rheumatology Copyright @ 2012 . All rights reserved. 
latent tuberculosis is recommended prior to anti-TNF, abatacept, and tocilizumab. Baseline antinuclear antibody (ANA) testing could be considered prior to starting anti-TNF. (Level IV; Strength D)

Summary of guidelines. The search identified 10 CPG and 3 CS addressing investigations prior to initiating biologics (AGREE rating: $\mathrm{R}=2, \mathrm{R}^{*}=10, \mathrm{WNR}=1$ ). Ten guidelines

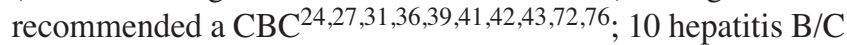
screening $19,24,27,31,39,41,42,43,74,76 ; 7$ HIV testing $19,24,38$, $39,41,42,43$; 6 liver enzymes ${ }^{24,31,36,39,74,76}$; and 2 creatinine $^{31,36}$ prior to treatment with a biologic. Nine guidelines included recommendations for anti-TNF, 4 of which recommended a baseline ANA ${ }^{19,39,66,76}$. Seven guidelines included recommendations for rituximab (RTX), 5 of which recommended quantitative immunoglobulins (Ig) $)^{19,27,31,42,43}$, and 2 recommended B cell levels ${ }^{19,42}$. All guidelines that addressed screening for latent tuberculosis infection recommended screening prior to anti-TNF therapy, abatacept (ABAT), and tocilizumab (TCZ).

Recommendation/supporting evidence. ARA $2010^{19}\left(\mathrm{R}^{*}\right)$ and ACR $2008^{36}$ (R).

Summary of evidence linked to recommendation. There was very limited evidence supporting recommendations in the available guidelines (all were based on expert opinion, or levels of evidence were not reported). 2008 ACR guidelines ${ }^{36}$ recommended ordering $\mathrm{CBC}$, liver transaminases, and creatinine prior to initiating any biologic, and screening for LTBI before anti-TNF and ABAT, based on expert opinion. 2010 Australian guidelines ${ }^{19}$ added ordering hepatitis $\mathrm{B} / \mathrm{C}$ (and HIV in high-risk patients) due to concerns regarding safety of biologics in patients with chronic infection; and ordering ANA prior to anti-TNF because of risk of drug-induced lupus. Evidence to recommendation. The panel recognized that there was only weak evidence supporting existing guidelines, yet agreed that recommendations made by the ACR and ARA were reasonable. Having a baseline ANA was not felt to be mandatory but could be considered, as it may be useful in patients who develop lupus-like symptoms. The panel agreed that there was insufficient evidence to recommend immunoglobulin screening or B cell levels prior to RTX, based on expert opinion. Investigations related to managing comorbidities or cardiovascular risk may also be necessary when treating with a biologic but were beyond the scope of the present guideline.

Barriers to implementation. None.

Recommendation 17:

Methotrexate (MTX) coprescription with biologics is recommended for improved efficacy. (Level I; Strength A)

Summary of guidelines. The search identified 9 CPG and 4 CS that addressed MTX coprescription with a biologic (AGREE rating: $R=4, R^{*}=9$ ). All guidelines recommended prescribing biologics with MTX; 8 added that etanercept (ETN)/adal- imumab (ADA) can also be used as monotherapy $^{2,19,26,31,35,39,73,74}$, and 8 added that DMARD other than MTX can be coprescribed ${ }^{1,19,22,26,36,39,75,77}$.

Recommendation/supporting evidence. EULAR $2010^{26}(\mathrm{R})$, Furst $2010^{77}\left(\mathrm{R}^{*}\right)$, Fautrel $2007^{39}\left(\mathrm{R}^{*}\right)$.

Summary of evidence linked to recommendation. EULAR 2010 guidelines performed a systematic review of RCT examining the efficacy of biologic agents licensed for use in RA and concluded that MTX coprescription with biologic agents is associated with improved efficacy ${ }^{78}$. Direct evidence for added efficacy was shown in trials that compared biologic plus MTX to biologic monotherapy (ADA, ETN, golimumab, rituximab, and tocilizumab); trials included for the remaining biologics [infliximab, certolizumab (CTZ), and abatacept (ABAT)] studied efficacy of the biologic in combination with MTX only. DMARD other than MTX have also been used in combination with biologic agents in RCT and observational studies $39,77,78$.

Evidence to recommendation. The panel agreed that there was strong evidence to recommend coprescription of MTX with biologic agents. In cases where MTX cannot be used, another DMARD is recommended. If coprescription with MTX or another DMARD is not possible, certain biologic agents may be used in monotherapy. Currently, ETN, ADA, CTZ, ABAT, and tocilizumab are licensed for use as monotherapy in Canada. Patients that have remained in a low disease state taking biologic monotherapy may not need the reintroduction of a DMARD.

Barriers to implementation. None.

Recommendation 18:

Anti-TNF therapy is recommended for the treatment of patients with RA after an inadequate response to DMARD. In exceptional circumstances involving patients with DMARD contraindications or high disease activity and poor prognostic factors (particularly early disease), anti-TNF therapy may be an option after failure of DMARD monotherapy or in DMARD-naive patients. (Level I; Strength A)

Summary of guidelines. The search identified 8 CPG and 10 CS that addressed indications for anti-TNF therapy (AGREE rating: $\left.R=5, R^{*}=12, W N R=1\right)$. All guidelines recommended use of anti-TNF after DMARD failure ${ }^{1,2,20,21,26}$, $27,29,31,34,35,36,39,40,51,71,74,75,77,79$. Twelve guidelines commented on the use of anti-TNF therapy in DMARD-naive patients; 6 considered use of anti-TNF as an option in certain situations ${ }^{21,26,27,36,39,77}$, and 6 concluded that there was insufficient evidence to recommend their use $\mathrm{e}^{1,29,40,71,74,79}$.

Recommendation/supporting evidence. EULAR $2010^{26}$ (R), Canadian Agency for Drugs and Technologies in Health $(\mathrm{CADTH})^{1}(\mathrm{R})$.

Summary of evidence linked to recommendation. Systematic Personal non-commercial use only. The Journal of Rheumatology Copyright @ 2012 . All rights reserved. 
reviews performed by EULAR 2010 guidelines ${ }^{26}$ and 2010 CADTH guidelines ${ }^{1}$ considered all anti-TNF agents [adalimumab (ADA), certolizumab (CTZ), etanercept (ETN), infliximab (IFX), golimumab (GOL)] and trials in both DMARD-IR and MTX-naive patients. There is direct RCT evidence of efficacy for all anti-TNF therapies in patients who have had an inadequate response to MTX. For IFX, ETN, $\mathrm{ADA}$, and GOL, there is also RCT evidence for efficacy in patients who are MTX-naive. Some patients in these trials were also DMARD-naive and all patients had early RA with high baseline disease activity. There were no head-to-head trials comparing anti-TNF.

Evidence to recommendation. The panel agreed that there was strong evidence that anti-TNF therapy is effective after failure of a DMARD or in patients who are MTX (or DMARD) naive. However, the panel also acknowledged that many patients respond well to initial DMARD therapy and considered the implications of using anti-TNF therapy in DMARD-naive patients, including added costs and potential risks. Therefore, the panel agreed that in most circumstances anti-TNF therapy should be used after a DMARD-IR. Anti-TNF therapy was acknowledged as an option in DMARD-naive patients or after failure of DMARD monotherapy in rare situations outlined in the recommendation, consistent with eligibility criteria for biologic trials in MTX-naive patients.

Barriers to implementation. Canadian provincial formularies restrict access to first-line biologic therapy.

Recommendation 19:

Abatacept is recommended for the treatment of patients with RA after an inadequate response to DMARD or anti-TNF therapy. (Level I; Strength A)

Summary of guidelines. The search identified 6 CPG and 1 CS that addressed indications for abatacept (ABAT) (AGREE ratings: $\mathrm{R}=4, \mathrm{R}^{*}=3$ ). Five guidelines recommended that $\mathrm{ABAT}$ may be used after an inadequate response or intolerance to either DMARD [including methotrexate (MTX)] or anti-TNF therapy $1,19,26,36,77$, EULAR 201026; however, qualified that current practice would be to use an anti-TNF first, and another guideline recommended ABAT only after failure of anti-TNF therapy ${ }^{27}$. Only one guideline, NICE $2008^{80}$, did not recommend ABAT. No guidelines provided situations in which ABAT may be preferred to other biologics.

Recommendation/supporting evidence. EULAR $2010^{26}$ (R), $\mathrm{CADTH}^{1}(\mathrm{R})$.

Summary of evidence linked to recommendation. Systematic reviews of RCT used to inform the EULAR 2010 guidelines $^{78}$ and 2010 CADTH guidelines ${ }^{1}$ provided direct RCT evidence supporting the efficacy of ABAT + MTX in patients with an inadequate response to MTX, and for ABAT + another DMARD in patients with inadequate response to anti-TNF therapy. The review also found RCT evidence for the efficacy of ABAT + MTX versus MTX monotherapy in patients who are DMARD-naive with high disease activity and poor prognostic factors.

Evidence to recommendation. The panel concluded that there was strong evidence that ABAT is effective after failure of DMARD or anti-TNF therapy. The panel also considered that there is evidence for the efficacy of ABAT in DMARD-naive patients, but agreed that, in the rare situations where a biologic is being considered as first-line therapy, an anti-TNF would be used.

\section{Barriers to implementation. None.}

Recommendation 20:

Rituximab is recommended for the treatment of patients with RF-positive RA after an inadequate response to DMARD or anti-TNF therapy. (Level I; Strength A)

Summary of guidelines. The search identified 7 CPG and 3 CS that addressed indications for rituximab (RTX) (AGREE rating: $R=5, R^{*}=5$ ). Four guidelines recommended that $R T X$ may be used after an inadequate response or intolerance to either DMARD (including MTX) or anti-TNF therapy ${ }^{26,31,36,77}$ and 6 recommended use of RTX only after failure of anti-TNF therapy $1,19,27,43,51,81,82$. Three guidelines emphasized that the efficacy of RTX relates to RF-positive patients ${ }^{26,43,77}$, although one suggests that RF-negative patients should still be considered for RTX treatment ${ }^{51}$. Smolen $2007^{82}$ added that RTX may be preferred over anti-TNF therapy in certain situations, including patients with a history of B cell lymphoma, multiple sclerosis, and concomitant vasculitis or overlap syndromes.

Recommendation/supporting evidence. EULAR $2010^{26}$ (R), Smolen $2007^{82}\left(\mathrm{R}^{*}\right)$.

Summary of evidence linked to recommendation. A systematic review of RCT used to inform the EULAR 2010 guidelines ${ }^{78}$ provided direct RCT evidence supporting the efficacy of RTX + MTX in patients with an inadequate response to MTX or other DMARD, and patients with an inadequate response to anti-TNF therapy. Smolen $2007^{82}$ highlighted that the efficacy of RTX in RF-negative patients is inconclusive due to limited data from small numbers of RF-negative patients. CADTH $2010^{1}$ in their systematic review of RCT referenced the same RCT evidence supporting the efficacy of RTX in DMARD-IR patients; however, the review did not consider RTX as an option in DMARD-IR patients due to current Health Canada restrictions on use of RTX only after failure of an anti-TNF.

Evidence to recommendation. The panel agreed that there was strong evidence that RTX is effective after failure of DMARD or anti-TNF therapy in RF-positive patients. The panel also agreed that in certain situations, including patients with a previous history of B cell lymphoma, LTBI, multiple sclerosis, and concomitant vasculitis or overlap syndromes, RTX may be preferred.

Barriers to implementation. Health Canada's current indica-

Personal non-commercial use only. The Journal of Rheumatology Copyright (C) 2012. All rights reserved. 
tions for RTX do not offer the option of accessing RTX in patients who have had an inadequate response to DMARD.

Recommendation 21:

Patients should not be expected to flare before they are retreated with rituximab (RTX). Retreatment can occur as early as 6 months if the patient has had an initial response but has persistent synovitis. (Level II, IV; Strength C)

Summary of guidelines. The search identified 4 CPG and 3 CS that addressed retreatment with RTX (AGREE rating: $\mathrm{R}=2$, $\mathrm{R}^{*}=5$ ). Four guidelines recommended retreatment after relapse or if patients have persistent disease activity ${ }^{19,31,42,82}$, and one guideline recommended retreatment only after relapse $\mathrm{H}^{43}$. The remaining 2 guidelines did not provide a specific recommendation ${ }^{77,81}$. In terms of timing, 6 guidelines recommended retreatment no earlier than every 6 months $19,31,42,43,81,82$. Furst $2010^{77}$ noted that some patients have been retreated as early as at 4 months.

Recommendation/supporting evidence: Furst $2010^{77}\left(\mathrm{R}^{*}\right)$, Smolen $2007^{82}\left(\mathrm{R}^{*}\right)$.

Summary of evidence linked to recommendation. Smolen $2007^{82}$ and Furst $2010^{77}$ refer to an open-label extension study of RTX retreatment ${ }^{83}$ that showed that retreatment at $\geq 4-6$ months in initial responders who experienced a flare or had residual disease was associated with improved disease control.

Evidence to recommendation. The panel considered that some patients who have an initial response to RTX treatment may not yet be at target. The panel uniformly agreed that patients should not be expected to flare before retreatment is given, and therefore added that retreatment can occur in the setting of persistent synovitis. This is in line with the open-label extension study of $\mathrm{RTX}^{83}$ and consistent with the concept of treating to target (see Recommendation 1).

Barriers to implementation. Most Canadian provincial formularies require patients with an initial response to RTX to experience flare in order to access RTX retreatment.

Recommendation 22:

Tocilizumab is recommended for the treatment of patients with RA after an inadequate response to DMARD or anti-TNF therapy. (Level I; Strength A)

Summary of guidelines. The search identified 5 CPG and 1 CS that addressed this question (AGREE rating: $R=2, R^{*}=4$ ). Five guidelines recommended that tocilizumab (TCZ) may be used after an inadequate response or intolerance to an adequate trial of an effective DMARD [including methotrexate (MTX)] or anti-TNF therapy ${ }^{19,24,26,72,77}$. Only one guideline, NICE $2010^{84}$, recommended that TCZ be used only after an inadequate response or intolerance to anti-TNF therapy and rituximab (RTX). Four guidelines recommended a dose of 8 $\mathrm{mg} / \mathrm{kg}$ every 4 weeks ${ }^{19,24,72,84}$ and 1 stated that $4 \mathrm{mg} / \mathrm{kg}$ can be used but was less effective as monotherapy in

\section{DMARD-IR ${ }^{77}$.}

Recommendation/supporting evidence. Furst $2010^{77}\left(\mathrm{R}^{*}\right)$, EULAR $2010^{26}$ (R).

Summary of evidence linked to recommendation. A systematic review of RCT used to inform the EULAR 2010 guidelines ${ }^{78}$ provided direct RCT evidence supporting the efficacy of TCZ in patients with an inadequate response to MTX or other DMARD, and in patients with an inadequate response to anti-TNF therapy. Furst $2010^{77}$ highlighted that although 4 $\mathrm{mg} / \mathrm{kg}$ can be used, TCZ trials showed improved efficacy with $8 \mathrm{mg} / \mathrm{kg}$ over $4 \mathrm{mg} / \mathrm{kg}$.

Evidence to recommendation. The panel agreed that there was strong evidence that TCZ is effective after failure of DMARD or anti-TNF therapy.

Barriers to implementation. Currently, Health Canada approval for dosing of TCZ is to start at $4 \mathrm{mg} / \mathrm{kg}$ and increase to $8 \mathrm{mg} / \mathrm{kg}$ based on clinical response.

Recommendation 23:

In patients who have failed treatment with 1 anti-TNF agent due to lack of efficacy or toxicity the following options are recommended: switch to another anti-TNF agent (I, II); switch to another biologic with a different mechanism of action [abatacept (ABAT), rituximab (RTX), tocilizumab (TCZ)] (I); or add MTX (or other DMARD) if the anti-TNF agent was used in monotherapy (II). (Level I, II; Strength B)

Summary of guidelines. The search identified 5 CPG that directly addressed treatment strategies after failure of an anti-TNF (AGREE rating: $\mathrm{R}=2, \mathrm{R}^{*}=3$ ). Four suggested either switching to another mechanism of action or trying a second anti-TNF with no preference ${ }^{19,26,27,39}$, while 1 recommended only switching to another mechanism of action ${ }^{1}$. Three guidelines also included adding methotrexate (MTX) or adjusting traditional DMARD therapy and dose/interval adjustment of infliximab (IFX) as options ${ }^{19,27,39}$. Only 1 guideline suggested that adalimumab (ADA) dose/interval adjustment can be considered ${ }^{19}$.

Recommendation/supporting evidence. EULAR $2010^{26}$ (R), CADTH $2010^{1}$ (R).

Summary of evidence linked to recommendation. A systematic review of RCT used to inform the EULAR 2010 guidelines $^{78}$ provided direct RCT evidence supporting the efficacy of RTX, ABAT, TCZ, and golimumab in patients who have failed 1 anti-TNF. CADTH referred to a health technology assessment performed by NICE on options for treatment with biologic agents after failure of an anti-TNF ${ }^{85}$, which concluded that switching to a different anti-TNF may have some benefit based on observational studies. CADTH 2010 also examined RCT evidence for dose escalation of biologics and found contradictory evidence for IFX ( 2 trials showing benefit and 1 showing no benefit) and found evidence against dose escalation of etanercept. There was no evidence provided to support

Personal non-commercial use only. The Journal of Rheumatology Copyright @ 2012 . All rights reserved. 
dose/interval adjustment of ADA. There are no head-to-head trials comparing different therapeutic strategies in patients who have failed the first anti-TNF ${ }^{19,27,39}$.

Evidence to recommendation. The panel agreed that there is sufficient evidence to support the role of a second anti-TNF agent or switching to a biologic with a different mechanism of action in patients who fail to respond to the first anti-TNF. As biologic therapy is generally more effective when given in combination with DMARD, adding MTX (or other DMARD if MTX is contraindicated) to biologic monotherapy could also be considered. However, the panel realizes that this situation should be rare, as DMARD coprescription is recommended for all biologic therapy (see Recommendation 15). Dose/interval adjustment of IFX may be an option; however, evidence is inconclusive. A preference for a particular therapeutic strategy could not be established due to lack of head-tohead trials, therefore the choice should be a shared decision between patient and physician.

Barriers to implementation. None.

Recommendation 24:

In patients who have failed treatment with 2 anti-TNF agents a switch to another biologic with a different mechanism of action [abatacept (ABAT), rituximab (RTX), tocilizumab (TCZ)] is recommended. (Level II/IV; Strength C)

Summary of guidelines. No guideline specifically made a recommendation regarding treatment strategies after failure of 2 anti-TNF. Two guidelines, however, commented that patients who fail to respond to 2 anti-TNF agents are unlikely to respond to a third ${ }^{27,39}$.

Recommendation/supporting evidence. SER $2010^{27}\left(\mathrm{R}^{*}\right)$.

Summary of evidence linked to recommendation. 2010 Spanish guidelines ${ }^{27}$ and a 2009 health technology assessment performed by $\mathrm{NICE}^{85}$ found that, in observational studies of patients who were switched to a third anti-TNF after failure of 2 , patients had lower durability and a blunted clinical response. RCT of ABAT, RTX, and TCZ after anti-TNF failure $^{86,87,88}$ and 1 RCT of golimumab ${ }^{89}$ included patients who previously failed more than 1 anti-TNF and in subgroup analysis showed some benefit in terms of ACR clinical response outcomes for patients who failed 2 anti-TNF.

Evidence to recommendation. The panel recognized that there was no direct evidence comparing different therapeutic strategies in patients failing $\geq 2$ anti-TNF. Based on the limited evidence extrapolated from RCT and observational studies, the panel agreed that switching to a different mechanism of action is currently the preferred therapeutic strategy for patients with $\geq 2$ prior TNF failures.

Barriers to implementation. None.

Recommendation 25:

In the absence of data on therapeutic strategies after failure of abatacept (ABAT), rituximab (RTX), or tocilizumab (TCZ), the following options can be considered: switch to any biologic not previously tried and failed, add/switch to a traditional DMARD not previously tried and failed, or enroll the patient in a clinical trial with a new agent. (Level IV; Strength D)

Summary of guidelines. No guideline specifically addressed this question. EULAR 2010 provides a treatment algorithm for patients with RA in which patients who fail ABAT, TCZ, RTX, or anti-TNF therapy may be treated with a biologic agent with a different mechanism of action ${ }^{26}$.

Recommendation/supporting evidence. This recommendation was generated based on consensus of the expert panel.

Summary of evidence linked to recommendation. There was no evidence provided in published guidelines regarding treatment options in patients failing RTX, TCZ, or ABAT.

Evidence to recommendation. In view of the lack of evidence evaluating efficacy of biologic or nonbiologic DMARD in patients with an inadequate response to ABAT, RTX, or TCZ, the panel considered possible strategies with potential benefits including switching the treatment to an agent with a different mechanism of action or to a nonbiologic DMARD, if not previously used. Offering enrollment into a clinical trial is also an option in patients who fail to respond to available therapies, although clinical trials, where appropriate, are an option at any time during the treatment of patients with RA. Lastly, as in any other failure scenario, alternative reasons for failure such as patient nonadherence to treatment (either partial or complete) and alternative diagnoses contributing to patients' symptoms (e.g., fibromyalgia) should also be explored with the patient and considered when deciding on the appropriate therapeutic strategy.

Barriers to implementation. None.

Recommendation 26:

If a patient achieves sustained remission after discontinuation of NSAID and glucocorticoids, a reduction in biologic and/or nonbiologic DMARD can be attempted with caution as a shared decision between patient and physician. (Level IV; Strength D)

Summary of guidelines. The search identified 5 CPG and 3 CS that addressed tapering strategies (AGREE rating: $\mathrm{R}=3, \mathrm{R}^{*}$ $=5$ ). All guidelines emphasized that there was limited evidence to support specific tapering strategies and/or suggested caution when considering tapering DMARD or biologic therapy $1,25,26,27,39,73,74,77$. Two guidelines suggested tapering biologic therapy prior to DMARD 26,27 , and 1 suggested that tapering either biologic or DMARD therapy can be considered, with no preference for sequencing ${ }^{39}$.

Recommendation/supporting evidence. EULAR $2010^{26}$ (R), Furst $2010^{77}\left(\mathrm{R}^{*}\right)$.

Summary of evidence linked to recommendation. EULAR 2010 guidelines $^{26}$ referred to a systematic review on withdrawal of traditional DMARD in patients with established RA Personal non-commercial use only. The Journal of Rheumatology Copyright @ 2012 . All rights reserved. 
greater than 2 years ${ }^{90}$. The authors concluded that in patients who achieved remission on DMARD, stopping treatment resulted in significantly more flares compared to patients who continued treatment. However, the pooled analysis included heterogeneous trials of variable quality. The largest trial $^{91}$ in the analysis included 285 patients who were in remission for at least 1 year. Among patients who were randomized to discontinue the DMARD therapy, 38\% experienced flare compared to $22 \%$ of patients who continued DMARD therapy. A followup study of the same patients showed that achieving remission in the patients who flared was more difficult ${ }^{92}$. Furst 2010 suggests that biologic therapy may be reduced without loss of effect, but did not provide citable evidence ${ }^{77}$. No guideline provided a schedule for tapering/withdrawing therapy, although EULAR 2010 suggested that patients should be in remission for at least 12 months before attempting to taper DMARD or biologic therapy based on expert opinion.

Evidence to recommendation. The panel considered that there is currently no validated definition for sustained remission in RA and that there are no appropriately designed RCT comparing tapering strategies for DMARD and biologics. The panel therefore recommended that tapering of either DMARD or biologic therapy could be attempted with caution in sustained remission after successfully discontinuing NSAID and glucocorticoids. There may be a tendency to consider tapering the biologic prior to tapering DMARD based on the added costs of biologic therapy and the limited evidence from small numbers of patients in biologic remission that have discontinued biologic therapy successfully. However, the risk of flare after discontinuing the biologic in patients who failed DMARD due to lack of efficacy should be considered. The decision of whether to taper or withdraw therapy should be made on a case-by-case basis after discussion of the risks and benefits with the patient. Patients should be monitored closely for flares, through either their rheumatologist or family physician. If the patient experiences a flare, they should consult their rheumatologist immediately, and ready access to the rheumatologist should be facilitated to minimize delays in the reinstitution of appropriate therapy.

Barriers to implementation. There may be limited access to timely consultation with a rheumatologist.

\section{DISCUSSION}

Five overarching principles and 26 treatment recommendations were developed by a Canadian national multidisciplinary working group based on a synthesis of international guidelines, supporting evidence from observational studies and RCT, and from expert consensus, taking into account the Canadian healthcare context. We anticipate that these recommendations will serve as useful knowledge to support decision-making for rheumatology health professionals and enhance the care of patients with RA. It is understood that there will be specific patient scenarios for which these recommendations may not be applicable and we emphasize that these recommendations should be used with the clinical judgment of the treating physician according to the needs of the patient and the unique clinical circumstance.

These recommendations were developed using a guideline adaptation approach modified from the ADAPTE framework. Developing recommendations through guideline adaptation allowed the working group to maximize efficiency, feasibility, and timeliness of the evidence review and dissemination of Canadian recommendations while using rigorous and systematic methods. Further, we introduced new methodological enhancements including a more sensitive search strategy, a custom grading system to allow harmonization of evidence systems across guidelines, and a new procedure for synthesizing individual recommendations organized according to key question $^{12}$. This enabled us to develop a comprehensive set of recommendations addressing a large number of a priori treatment questions identified through a national needs assessment survey of Canadian rheumatology professionals ${ }^{13}$, and to contextualize each newly developed recommendation within all international practice recommendations. Supporting evidence from observational studies as well as RCT linked to each recommendation was reviewed in detail, and potential Canadian healthcare barriers that may affect guideline applicability were highlighted within the discussion of each recommendation to facilitate implementation.

There are limitations to consider when interpreting this guidance. A systematic review of original literature was not performed to inform recommendations, and the possibility that relevant studies were missed cannot be ruled out. These Canadian recommendations, however, were based on a systematic review and quality appraisal of all international practice recommendations published through June 2010, and emphasized recent guidelines of high methodological quality that included systematic reviews and citable evidence. Second, the custom system for assigning levels of evidence was based on study design and did not take into account additional criteria for assessing risk of bias within studies identified by more detailed evidence systems ${ }^{93}$. The variable evidence systems used by different guideline developers included in the review, however, could not be reconciled by applying a detailed evidence system. Therefore, a simplified system was applied across all guidelines to enable comparability and the original literature linked to each recommendation as well as the Canadian guideline working group's interpretation of the literature (and, where applicable, other interpretations by different guideline development groups), were discussed in detail in the supporting text of each recommendation.

Future studies that would help inform evidence-based practice include: (a) head-to-head trials examining the comparative effectiveness of treatment with traditional DMARD combinations versus DMARD + biologic, and of the various biologic treatment strategies (including dose escalation) after failure of DMARD, anti-TNF, and newer biologic classes abatacept, rituximab, tocilizumab, respectively; (b) longitudi-

Personal non-commercial use only. The Journal of Rheumatology Copyright @ 2012 . All rights reserved. 
nal studies examining predictors of response to specific drug therapies/drug classes, and of the longterm effects of different DMARD and biologic tapering/withdrawal strategies on clinical and quality of life outcomes; and (c) diagnostic studies comparing the feasibility, reliability, and sensitivity to change of imaging technologies such as ultrasound and magnetic resonance imaging in comparison with traditional radiographs in the assessment of patients with RA.

Conclusion. Recommendations were developed by a Canadian national multidisciplinary working group as a knowledge tool to support decision-making for rheumatology health professionals and to promote best practices in the healthcare of persons with RA.

\section{REFERENCES}

1. Canadian Agency for Drugs and Technology in Health. Clinical and economic overview: Biological response modifier agents for adults with rheumatoid arthritis; 2010. [Internet. Accessed July 14, 2011.] Available from: www.cadth.ca/media/pdf/TR_RA_Clinical_and_ Economic_Overview_e.pdf

2. Haraoui B. Canadian Rheumatology Association position on the use of biologic agents for the treatment of rheumatoid arthritis; 2002. [Internet. Accessed July 14, 2011.] Available from: http://www.rheum.ca/en/ContentPage. asp?sid=81

3. Gettings L. Psychological well-being in rheumatoid arthritis: a review of the literature. Musculoskeletal Care 2010;8:99-106.

4. Singh JA, Christensen R, Wells GA, Suarez-Almazor ME, Buchbinder R, Lopez-Olivo MA, et al. Biologics for rheumatoid arthritis: an overview of Cochrane reviews. Cochrane Database Syst Rev 2009;4:CD007848.

5. Davis D, Goldman J, Palda VA. Canadian Medical Association handbook on clinical practice guidelines. CMAJ 2007;177:1221-6.

6. Lopez-Olivo MA, Kallen MA, Ortiz Z, Skidmore B, Suarez-Almazor ME. Quality appraisal of clinical practice guidelines and consensus statements on the use of biologic agents in rheumatoid arthritis: a systematic review. Arthritis Rheum 2008;59:1625-38

7. Hazlewood G, Schieir O, Akhavan P, Bykerk V, Bombardier C. A systematic review and quality appraisal of guidelines on the pharmacological treatment of rheumatoid arthritis [abstract]. Ann Rheum Dis 2010;69 Suppl 3:479.

8. Arnett FC, Edworthy SM, Bloch DA, McShane DJ, Fries JF, Cooper NS, et al. The American Rheumatism Association 1987 revised criteria for the classification of rheumatoid arthritis. Arthritis Rheum 1988;31:315-24.

9. Aletaha D, Neogi T, Silman AJ, Funovits J, Felson DT, Bingham CO 3rd, et al. 2010 Rheumatoid arthritis classification criteria: an American College of Rheumatology/European League Against Rheumatism collaborative initiative. Arthritis Rheum 2010;62:2569-81.

10. Bombardier C, Akhavan P, Hazlewood G, Schieir O, Dooley A, Haraoui B, et al. Canadian Rheumatology Association (CRA) recommendations for the pharmacological management of rheumatoid arthritis with traditional and biologic disease modifying anti-rheumatic drugs: Part II: Safety. J Rheumatol 2011;38: [in press].

11. Fervers B, Burgers JS, Haugh MC, Latreille J, Mlika-Cabanne N, Paquet L, et al. Adaptation of clinical guidelines: literature review and proposition for a framework and procedure. Int J Qual Health Care 2006;18:167-76.

12. Schieir O, Hazlewood G, Akhavan P, Bykerk V, Bombardier C. Time to ADAPTE: A novel methodology for the development of national clinical practice guidelines to expedite dissemination [abstract]. Ann Rheum Dis 2010;69 Suppl 3:652.

13. Bykerk V, Schieir O, Akhavan P, Hazlewood G, Cheng C, Bombardier C. Emerging issues in the pharmacological management of rheumatoid arthritis: Results of a national needs assessment survey identifying practice variations for the development of Canadian Rheumatology Association Clinical practice recommendations. J Rheumatol 2011;38:[Epub ahead of print Sept 1]

14. AGREE Collaboration. Development and validation of an international appraisal instrument for assessing the quality of clinical practice guidelines: the AGREE project. Qual Saf Health Care 2003;12:18-23.

15. Canadian Agency for Drugs and Technology in Health. Grey matters: a practical search tool for evidence-based medicine; 2009. [Internet. Accessed July 14, 2011.] Available from: http://www.cadth.ca/index.php/en/cadth/products/grey-matters

16. Scottish Intercollegiate Guidelines Network (SIGN). SIGN 50: A guideline developer's handbook. 2008; [Internet. Accessed July 14, 2011.] Available from: http://www.sign.ac.uk/guidelines/ fulltext/50/index.html

17. Shiffman RN, Dixon J, Brandt C, Essaihi A, Hsiao A, Michel G, et al. The Guideline Implementability Appraisal (GLIA): development of an instrument to identify obstacles to guideline implementation. BMC Med Inform Decis Mak 2005;5:23.

18. Shiffman RN, Shekelle P, Overhage JM, Slutsky J, Grimshaw J, Deshpande AM. Standardized reporting of clinical practice guidelines: a proposal from the Conference on Guideline Standardization. Ann Intern Med 2003;139:493-8.

19. Australian Rheumatology Association (ARA). Updated recommendations for the use of biological agents for the treatment of rheumatic diseases; 2010. [Internet. Accessed Aug 25, 2011.] Available from: http://www.rheumatology.org.au/otherpages/ biological-guidelines.asp

20. Cardiel MH. First Latin American position paper on the pharmacological treatment of rheumatoid arthritis. Rheumatology 2006;45 Suppl 2:ii7-ii22.

21. Kiely PD, Brown AK, Edwards CJ, O'Reilly DT, Ostor AJ, Quinn $\mathrm{M}$, et al. Contemporary treatment principles for early rheumatoid arthritis: A consensus statement. Rheumatology 2009;48:765-72.

22. Luqmani R, Hennell S, Estrach C, Birrell F, Bosworth A, Davenport G, et al. British Society for Rheumatology and British Health Professionals in Rheumatology guideline for the management of rheumatoid arthritis (the first two years). Rheumatology 2006;45:1167-9.

23. National Institute for Clinical Excellence (NICE). Rheumatoid arthritis: The management of rheumatoid arthritis in adults: NICE clinical guidance 79; 2009. [Internet. Accessed July 14, 2011.] Available from: http://www.nice.org.uk/nicemedia/pdf/CG79NICEGuideline.pdf

24. Pham T, Claudepierre P, Constantin A, de Bandt M, Fautrel B, Gossec L, et al. Tocilizumab: therapy and safety management. Joint Bone Spine 2010;77 Suppl 1:S3-100.

25. Smolen JS, Aletaha D, Bijlsma JW, Breedveld FC, Boumpas D, Burmester G, et al. Treating rheumatoid arthritis to target: recommendations of an international task force. Ann Rheum Dis 2010;69:631-7.

26. Smolen JS, Landewe R, Breedveld FC, Dougados M, Emery P, Gaujoux-Viala C, et al. EULAR recommendations for the management of rheumatoid arthritis with synthetic and biological disease-modifying antirheumatic drugs. Ann Rheum Dis 2010;69:964-75.

27. Spanish Society of Rheumatology. Update of the consensus statement of the Spanish Society of Rheumatology on the management of biologic therapies in rheumatoid arthritis. Reumatol 
Clin 2010;6:23-36.

28. The Royal Australian College of General Practitioners. Clinical guidelines for diagnosis and management of early rheumatoid arthritis; 2008. [Internet. Accessed July 14, 2011.] Available from: www.healthnetworks.health.wa.gov.au/docs/Clinical_guidelines_ Rheumatoid_Arthritis.pdf; http://www.racgp.org.au/guidelines/ musculoskeletaldiseases

29. Wolfe F, Cush JJ, O’Dell JR, Kavanaugh A, Kremer JM, Lane NE, et al. Consensus recommendations for the assessment and treatment of rheumatoid arthritis. J Rheumatol 2001;28:1423-30.

30. Luqmani R, Hennell S, Estrach C, Basher D, Birrell F, Bosworth A, et al. British Society for Rheumatology and British Health Professionals in Rheumatology guideline for the management of rheumatoid arthritis (after the first 2 years). Rheumatology 2009;48:436-9.

31. Misra R, Sharma BL, Gupta R, Pandya S, Agarwal S, Agarwal P, et al. Indian Rheumatology Association consensus statement on the management of adults with rheumatoid arthritis. Indian J Rheumatol 2008;3 Suppl:S1-S16.

32. Scottish Intercollegiate Guidelines Network (SIGN). Management of early rheumatoid arthritis: SIGN Publication No. 48 2000; [Internet. Accessed July 14, 2011.] Available from: http://www.sign.ac.uk/guidelines/fulltext/48/index.html

33. Combe B, Landewe R, Lukas C, Bolosiu HD, Breedveld F, Dougados $\mathrm{M}$, et al. EULAR recommendations for the management of early arthritis: Report of a task force of the European Standing Committee for International Clinical Studies Including Therapeutics (ESCISIT). Ann Rheum Dis 2007;66:34-45.

34. Kalla AA, Stanwix A, Gotlieb D, Asherson RA, Mody GM. Rheumatoid arthritis: Clinical guideline 2003. South African Med J 2003;93:991-1011.

35. National Institute for Clinical Excellence (NICE). Adalimumab, etanercept and infliximab for the treatment of rheumatoid arthritis: NICE technology appraisal guidance 130 (includes a review of technology appraisal guidance 36); 2007. [Internet. Accessed July 14, 2011.] Available from: http://www.nice.org.uk/TA130

36. Saag KG, Teng GG, Patkar NM, Anuntiyo J, Finney C, Curtis JR, et al. American College of Rheumatology 2008 recommendations for the use of nonbiologic and biologic disease-modifying antirheumatic drugs in rheumatoid arthritis. Arthritis Care Res 2008;59:762-84.

37. van Jaarsveld CH, ter Borg EJ, Jacobs JW, Schellekens GA, Gmelig-Meyling FH, van Booma-Frankfort C, et al. The prognostic value of the antiperinuclear factor, anti-citrullinated peptide antibodies and rheumatoid factor in early rheumatoid arthritis. Clin Exp Rheumatol 1999;17:689-97.

38. Pham T, Gossec L, Fautrel B, Combe B, Flipo RM, Goupille P, et al. Physical examination and laboratory tests in the management of patients with rheumatoid arthritis: Development of recommendations for clinical practice based on published evidence and expert opinion. Joint Bone Spine 2005;72:222-8.

39. Fautrel B, Pham T, Mouterde G, Le Loet X, Goupille P, Guillemin F, et al. Recommendations of the French Society for Rheumatology regarding TNF alpha antagonist therapy in patients with rheumatoid arthritis. Joint Bone Spine 2007;74:627-37.

40. Deighton C, Hyrich K, Ding T, Ledingham J, Lunt M, Luqmani R, et al. BSR and BHPR rheumatoid arthritis guidelines on eligibility criteria for the first biological therapy. Rheumatology 2010;49:1197-99.

41. Pham T, Claudepierre P, Constantin A, Fautrel B, Gossec L, Gottenberg JE, et al. Abatacept therapy and safety management. Joint Bone Spine 2009;76 Suppl 1:S3-S55.

42. Pham T, Fautrel B, Gottenberg JE, Goupille P, Hachulla E, Masson $\mathrm{C}$, et al. Rituximab (MabThera) therapy and safety management. Clinical tool guide. Joint Bone Spine 2008;75 Suppl 1:S1-99.
43. Soriano ER, Galarza-Maldonado C, Cardiel MH, Pons-Estel BA, Massardo L, Caballero-Uribe CV, et al. Use of rituximab for the treatment of rheumatoid arthritis: The Latin American context. Rheumatology 2008;47:1097-9.

44. Knevel R, Schoels M, Huizinga TW, Aletaha D, Burmester GR, Combe B, et al. Current evidence for a strategic approach to the management of rheumatoid arthritis with disease-modifying antirheumatic drugs: a systematic literature review informing the EULAR recommendations for the management of rheumatoid arthritis. Ann Rheum Dis 2010;69:987-94.

45. Grigor C, Capell H, Stirling A, McMahon AD, Lock P, Vallance R, et al. Effect of a treatment strategy of tight control for rheumatoid arthritis (the TICORA study): a single-blind randomised controlled trial. Lancet 2004;364:263-9.

46. Verstappen SM, Jacobs JW, van der Veen MJ, Heurkens AH, Schenk Y, ter Borg EJ, et al. Intensive treatment with methotrexate in early rheumatoid arthritis: aiming for remission. Computer Assisted Management in Early Rheumatoid Arthritis (CAMERA, an open-label strategy trial). Ann Rheum Dis 2007;66:1443-9.

47. Fransen J, Moens HB, Speyer I, van Riel PL. Effectiveness of systematic monitoring of rheumatoid arthritis disease activity in daily practice: a multicentre, cluster randomised controlled trial. Ann Rheum Dis 2005;64:1294-8.

48. Kirwan JR, Mitchell K, Hewlett S, Hehir M, Pollock J, Memel D, et al. Clinical and psychological outcome from a randomized controlled trial of patient-initiated direct-access hospital follow-up for rheumatoid arthritis extended to 4 years. Rheumatology 2003;42:422-6.

49. Hewlett S, Kirwan J, Pollock J, Mitchell K, Hehir M, Blair PS, et al. Patient initiated outpatient follow up in rheumatoid arthritis: six year randomised controlled trial. BMJ 2005;330:171.

50. Chakravarty K, McDonald H, Pullar T, Taggart A, Chalmers R, Oliver S, et al. BSR/BHPR guideline for disease-modifying anti-rheumatic drug (DMARD) therapy in consultation with the British Association of Dermatologists. Rheumatology 2008;47:924-5.

51. Massardo L, Suarez-Almazor ME, Cardiel MH, Nava A, Levy RA, Laurindo I, et al. Management of patients with rheumatoid arthritis in Latin America: a consensus position paper from Pan-American League of Associations of Rheumatology and Grupo Latino Americano De Estudio De Artritis Reumatoide. J Clin Rheumatol 2009;15:203-10.

52. Meyer O, de Bandt M, Berthelot JM, Cantagrel A, Combe B, Fautrel B, et al. Clinical practice format for choosing a second-line disease modifying anti-rheumatic drug in early rheumatoid arthritis after failure of 6 months' first-line DMARD therapy. Joint Bone Spine 2007;74:73-8.

53. Aletaha D, Funovits J, Breedveld FC, Sharp J, Segurado O, Smolen JS. Rheumatoid arthritis joint progression in sustained remission is determined by disease activity levels preceding the period of radiographic assessment. Arthritis Rheum 2009;60:1242-9.

54. Spanish Society of Rheumatology. Update of the clinical practice guideline for the management of rheumatoid arthritis in Spain; 2007. [Internet. Accessed July 14, 2011.] Available from: http://www.ser.es/ArchivosDESCARGABLES/Proyectos/ GUIPCAR_2007/GUIPCAR2007-ENG.pdf

55. Gorter SL, Bijlsma JW, Cutolo M, Gomez-Reino J, Kouloumas M, Smolen JS, et al. Current evidence for the management of rheumatoid arthritis with glucocorticoids: a systematic literature review informing the EULAR recommendations for the management of rheumatoid arthritis. Ann Rheum Dis 2010;69:1010-4.

56. Hoes JN, Jacobs JW, Boers M, Boumpas D, Buttgereit F, Caeyers $\mathrm{N}$, et al. EULAR evidence-based recommendations on the management of systemic glucocorticoid therapy in rheumatic 
diseases. Ann Rheum Dis 2007;66:1560-7.

57. Bykerk VP, Baron M, Boire G, Haraoui B, Khraishi M, LeClercq S, et al. Canadian consensus statement on early optimal therapy in early rheumatoid arthritis; 2004. [Internet. Accessed July 14, 2011.] Available from: http://www.rheum.ca/en/ContentPage.asp?sid=81

58. Maddison P, Kiely P, Kirkham B, Lawson T, Moots R, Proudfoot D, et al. Leflunomide in rheumatoid arthritis: Recommendations through a process of consensus. Rheumatology 2005;44:280-6.

59. Le Loet X, Berthelot JM, Cantagrel A, Combe B, De Bandt M, Fautrel B, et al. Clinical practice decision tree for the choice of the first disease modifying antirheumatic drug for very early rheumatoid arthritis: a 2004 proposal of the French Society of Rheumatology. Ann Rheum Dis 2006;65:45-50.

60. Salliot C, van der Heijde D. Long-term safety of methotrexate monotherapy in patients with rheumatoid arthritis: a systematic literature research. Ann Rheum Dis 2009;68:1100-4.

61. Pavy S, Constantin A, Pham T, Gossec L, Maillefert JF, Cantagrel A, et al. Methotrexate therapy for rheumatoid arthritis: clinical practice guidelines based on published evidence and expert opinion. Joint Bone Spine 2006;73:388-95.

62. Visser K, Katchamart W, Loza E, Martinez-Lopez JA, Salliot C, Trudeau J, et al. Multinational evidence-based recommendations for the use of methotrexate in rheumatic disorders with a focus on rheumatoid arthritis: integrating systematic literature research and expert opinion of a broad international panel of rheumatologists in the 3E Initiative. Ann Rheum Dis 2009;68:1086-93.

63. Furst DE, Koehnke R, Burmeister LF, Kohler J, Cargill I. Increasing methotrexate effect with increasing dose in the treatment of resistant rheumatoid arthritis. J Rheumatol 1989;16:313-20.

64. Schnabel A, Reinhold-Keller E, Willmann V, Gross WL. Tolerability of methotrexate starting with 15 or $25 \mathrm{mg} /$ week for rheumatoid arthritis. Rheumatol Int 1994;14:33-8.

65. Bakker MF, Jacobs JW, Welsing PM, van der Werf JH, Linn-Rasker $\mathrm{SP}$, van der Veen MJ, et al. Are switches from oral to subcutaneous methotrexate or addition of ciclosporin to methotrexate useful steps in a tight control treatment strategy for rheumatoid arthritis? A post hoc analysis of the CAMERA study. Ann Rheum Dis 2010;69:1849-52.

66. GPAC: Guidelines and Protocols Advisory Committee. Rheumatoid arthritis: diagnosis and management; 2006. [Internet. Accessed July 14, 2011.] Available from: http://www.bcguidelines.ca/gpac/

67. Gaujoux-Viala C, Smolen JS, Landewe R, Dougados M, Kvien TK, Mola EM, et al. Current evidence for the management of rheumatoid arthritis with synthetic disease-modifying antirheumatic drugs: a systematic literature review informing the EULAR recommendations for the management of rheumatoid arthritis. Ann Rheum Dis 2010;69:1004-9.

68. Katchamart W, Trudeau J, Phumethum V, Bombardier C. Efficacy and toxicity of methotrexate (MTX) monotherapy versus MTX combination therapy with non-biological disease-modifying antirheumatic drugs in rheumatoid arthritis: a systematic review and meta-analysis. Ann Rheum Dis 2009;68:1105-12.

69. Kremer JM, Genovese MC, Cannon GW, Caldwell JR, Cush JJ, Furst DE, et al. Concomitant leflunomide therapy in patients with active rheumatoid arthritis despite stable doses of methotrexate. A randomized, double-blind, placebo-controlled trial. Ann Intern Med 2002; $137: 726-33$.

70. FDA. FDA Drug Safety Communication: New boxed warning for severe liver injury with arthritis drug Arava (leflunomide); 2010. [Internet. Accessed July 14, 2011.] Available from: http://www.fda.gov/Drugs/DrugSafety/PostmarketDrugSafetyInfor mationforPatientsandProviders/ucm218679.htm

71. Emery P, Reginster JY, Appelboom T, Breedveld FC, Edelmann E, Kekow J, et al. WHO collaborating centre consensus meeting on anti-cytokine therapy in rheumatoid arthritis. Rheumatology
2001;40:699-702.

72. Koike R, Harigai M, Atsumi T, Amano K, Kawai S, Saito K, et al. Japan College of Rheumatology 2009 guidelines for the use of tocilizumab, a humanized anti-interleukin-6 receptor monoclonal antibody, in rheumatoid arthritis. Mod Rheumatol 2009;19:351-7.

73. Ledingham J, Deighton C. Update on the British Society for Rheumatology guidelines for prescribing TNF alpha blockers in adults with rheumatoid arthritis (update of previous guidelines of April 2001). Rheumatology 2005;44:157-63.

74. Mok CC. Consensus on the use and monitoring of anti-TNF-alpha therapies for rheumatic diseases in Hong Kong 2005. APLAR J Rheumatol 2006;9:175-80.

75. Royal College of Nursing (RCN). Assessing, managing and monitoring biologic therapies for inflammatory arthritis: guidance for rheumatology practitioners. Musculoskeletal Care 2003;1:135-40.

76. Pham T, Claudepierre P, Deprez X, Fautrel B, Goupille P, Hilliquin $\mathrm{P}$, et al. Anti-TNF alpha therapy and safety monitoring. Clinical tool guide elaborated by the Club Rhumatismes et Inflammations (CRI), section of the French Society of Rheumatology (Societe Francaise de Rhumatologie, SFR). Joint Bone Spine 2005;72 Suppl 1:S1-58.

77. Furst DE, Keystone EC, Fleischmann R, Mease P, Breedveld FC, Smolen JS, et al. Updated consensus statement on biological agents for the treatment of rheumatic diseases, 2009. Ann Rheum Dis 2010;69 Suppl 1:i2-29.

78. Nam JL, Winthrop KL, van Vollenhoven RF, Pavelka K, Valesini G, Hensor EM, et al. Current evidence for the management of rheumatoid arthritis with biological disease-modifying antirheumatic drugs: a systematic literature review informing the EULAR recommendations for the management of RA. Ann Rheum Dis 2010;69:976-86.

79. Smolen JS, Breedveld FC, Burmester GR, Combe B, Emery P, Kalden JR, et al. Consensus statement on the initiation and continuation of tumour necrosis factor blocking therapies in rheumatoid arthritis. Ann Rheum Dis 2000;59:504-5.

80. National Institute for Clinical Excellence (NICE). Abatacept for the treatment of rheumatoid arthritis: NICE technology appraisal guidance 141; 2008. [Internet. Accessed July 14, 2011.] Available from: http://www.nice.org.uk/nicemedia/pdf/TA141 guidance.pdf

81. National Institute for Clinical Excellence (NICE). Rituximab for the treatment of rheumatoid arthritis: NICE technology appraisal guidance 126; 2007. [Internet. Accessed July 14, 2011.] Available from: http://www.nice.org.uk/nicemedia/pdf/TA126guidance.pdf

82. Smolen JS, Keystone EC, Emery P, Breedveld FC, Betteridge N, Burmester GR, et al. Consensus statement on the use of rituximab in patients with rheumatoid arthritis. Ann Rheum Dis 2007;66:143-50.

83. Keystone E, Fleischmann R, Emery P, Furst DE, van Vollenhoven $\mathrm{R}$, Bathon J, et al. Safety and efficacy of additional courses of rituximab in patients with active rheumatoid arthritis: an open-label extension analysis. Arthritis Rheum 2007;56:3896-908.

84. National Institute for Clinical Excellence (NICE). Tocilizumab for the treatment of rheumatoid arthritis; 2010. [Internet. Accessed July 14, 2011.] Available from: http://www.nice.org.uk/nicemedia/live/13100/50391/50391.pdf

85. National Institute for Health and Clinical Excellence. Adalimumab, etanercept, infliximab, rituximab and abatacept for the treatment of rheumatoid arthritis after the failure of a TNF inhibitor: a systematic review and economic evaluation; 2009 [Internet. Accessed July 14, 2011]. Available from: http://www.nice.org.uk/ nicemedia/pdf/RheumatoidArthritisAssessmentReport.pdf

86. Cohen SB, Emery P, Greenwald MW, Dougados M, Furie RA, Genovese MC, et al. Rituximab for rheumatoid arthritis refractory to anti-tumor necrosis factor therapy: Results of a multicenter, 
randomized, double-blind, placebo-controlled, phase III trial evaluating primary efficacy and safety at twenty-four weeks. Arthritis Rheum 2006;54:2793-806.

87. Genovese MC, Becker JC, Schiff M, Luggen M, Sherrer Y, Kremer $\mathrm{J}$, et al. Abatacept for rheumatoid arthritis refractory to tumor necrosis factor alpha inhibition. N Engl J Med 2005;353:1114-23.

88. Emery P, Keystone E, Tony HP, Cantagrel A, van Vollenhoven R, Sanchez A, et al. IL-6 receptor inhibition with tocilizumab improves treatment outcomes in patients with rheumatoid arthritis refractory to anti-tumour necrosis factor biologicals: results from a 24-week multicentre randomised placebo-controlled trial. Ann Rheum Dis 2008;67:1516-23.

89. Smolen JS, Kay J, Doyle MK, Landewe R, Matteson EL, Wollenhaupt $\mathbf{J}$, et al. Golimumab in patients with active rheumatoid arthritis after treatment with tumour necrosis factor alpha inhibitors (GO-AFTER study): a multicentre, randomised, double-blind, placebo-controlled, phase III trial. Lancet 2009;374:210-21.

90. O'Mahony R, Richards A, Deighton C, Scott D. Withdrawal of disease-modifying antirheumatic drugs in patients with rheumatoid arthritis: a systematic review and meta-analysis. Ann Rheum Dis 2010;69:1823-6.

91. ten Wolde S, Breedveld FC, Hermans J, Vandenbroucke JP, van de Laar MA, Markusse HM, et al. Randomised placebo-controlled study of stopping second-line drugs in rheumatoid arthritis. Lancet 1996;347:347-52.
92. ten Wolde S, Hermans J, Breedveld FC, Dijkmans BA. Effect of resumption of second line drugs in patients with rheumatoid arthritis that flared up after treatment discontinuation. Ann Rheum Dis 1997;56:235-9.

93. Guyatt GH, Oxman AD, Vist GE, Kunz R, Falck-Ytter Y, Alonso-Coello P, et al. GRADE: an emerging consensus on rating quality of evidence and strength of recommendations. BMJ 2008;336:924-6.

94. Felson DT, Smolen JS, Wells G, Zhang B, van Tuyl LH, Funovits $\mathrm{J}$, et al. American College of Rheumatology/European League Against Rheumatism provisional definition of remission in rheumatoid arthritis for clinical trials. Ann Rheum Dis 2011;70:404-13.

95. Khanna D, Oh M, Furst DE, Ranganath V, Gold RH, Sharp JT, et al. Evaluation of the preliminary definitions of minimal disease activity and remission in an early seropositive rheumatoid arthritis cohort. Arthritis Rheum 2007;57:440-7.

96. Pincus T, Yazici Y, Bergman MJ. RAPID3, an index to assess and monitor patients with rheumatoid arthritis, without formal joint counts: similar results to DAS28 and CDAI in clinical trials and clinical care. Rheum Dis Clin North Am 2009;35:773-8, viii.

97. Aletaha D, Ward MM, Machold KP, Nell VP, Stamm T, Smolen JS. Remission and active disease in rheumatoid arthritis: defining criteria for disease activity states. Arthritis Rheum $2005 ; 52: 2625-36$. 
Appendix 1. Individual author conflicts of interest.

\begin{tabular}{|c|c|c|c|c|c|c|c|c|}
\hline $\begin{array}{l}\text { Working } \\
\text { Group } \\
\text { Member }\end{array}$ & $\begin{array}{l}\text { Involvement in } \\
\text { development of } \\
\text { guidelines } \\
\text { considered in } \\
\text { the systematic } \\
\text { review }\end{array}$ & $\begin{array}{l}\text { Involvement in } \\
\text { endorsement of } \\
\text { guidelines } \\
\text { considered in } \\
\text { the systematic } \\
\text { review }\end{array}$ & $\begin{array}{l}\text { Past/current } \\
\text { employment by } \\
\text { entity having a } \\
\text { commercial } \\
\text { interest in CDN } \\
\text { RA guidelines }\end{array}$ & $\begin{array}{l}\text { Past/current } \\
\text { consultant for } \\
\text { entity having a } \\
\text { commercial } \\
\text { interest in CDN RA } \\
\text { guidelines }\end{array}$ & $\begin{array}{l}\text { Ownership } \\
\text { interests (e.g., } \\
\text { stocks) in any } \\
\text { entity with a } \\
\text { commercial } \\
\text { interest in } \\
\text { CDN RA } \\
\text { guidelines }\end{array}$ & $\begin{array}{l}\text { Past/current } \\
\text { recipient of } \\
\text { research funds } \\
\text { from any entity with } \\
\text { a commercial } \\
\text { interest in CDN RA } \\
\text { guidelines } \\
>\$ 10,000\end{array}$ & $\begin{array}{l}\text { Past/current } \\
\text { recipient of } \\
\text { honoraria from any } \\
\text { entity with a } \\
\text { commercial interest } \\
\text { in CDN RA } \\
\text { guidelines } \\
>\$ 10,000\end{array}$ & $\begin{array}{l}\text { Other potential } \\
\text { conflicts }\end{array}$ \\
\hline $\begin{array}{l}\text { Akhavan, } \\
\text { Pooneh }\end{array}$ & No & No & No & No & No & $\begin{array}{l}\text { Yes: } \\
\text { UCB/CRA/TAS } \\
\text { Fellowship Award }\end{array}$ & Yes: Abbott & No \\
\hline $\begin{array}{l}\text { Bombardier, } \\
\text { Claire }\end{array}$ & $\begin{array}{l}\text { Yes: } \\
\text { Saag 2008, } \\
\text { Visser } 2009\end{array}$ & No & No & $\begin{array}{l}\text { Yes: Abbott, } \\
\text { Amgen, } \\
\text { Biogen Idec. } \\
\text { Roche, Merck, } \\
\text { Pfizer, Schering, } \\
\text { Wyeth }\end{array}$ & No & $\begin{array}{l}\text { Yes: Abbott, } \\
\text { Roche, UCB, } \\
\text { Merck, BMS }\end{array}$ & $\begin{array}{l}\text { Yes: Abbott, } \\
\text { Amgen, Bayer, } \\
\text { Biogen Idec, } \\
\text { Roche, Labopharm, } \\
\text { Merck, Pfizer, } \\
\text { Schering, Wyeth }\end{array}$ & No \\
\hline $\begin{array}{l}\text { Bykerk, } \\
\text { Vivian }\end{array}$ & $\begin{array}{l}\text { Yes: } \\
\text { Visser 2009, } \\
\text { Bykerk } 2004\end{array}$ & No & No & $\begin{array}{l}\text { Yes: Amgen, } \\
\text { Wyeth, Abbott, } \\
\text { Schering, BMS } \\
\text { Roche, Pfizer } \\
\text { Sanofi-Aventis }\end{array}$ & No & $\begin{array}{l}\text { Yes: Amgen, } \\
\text { Wyeth, Abbott, } \\
\text { Schering, BMS, } \\
\text { Roche, Pfizer }\end{array}$ & $\begin{array}{l}\text { Yes: Amgen, } \\
\text { Wyeth, Abbott, } \\
\text { Sanofi-Aventis, } \\
\text { Roche }\end{array}$ & No \\
\hline $\begin{array}{l}\text { Dooley, } \\
\text { Anne }\end{array}$ & No & No & No & No & No & No & No & No \\
\hline $\begin{array}{l}\text { Haraoui, } \\
\text { Boulos }\end{array}$ & $\begin{array}{l}\text { Yes: } \\
\text { Haraoui 2002, } \\
\text { Visser 2009, } \\
\text { Bykerk } 2004\end{array}$ & No & No & $\begin{array}{l}\text { Yes: Abbott, } \\
\text { Amgen, BMS, } \\
\text { Schering/Merck, } \\
\text { UCB, Roche, } \\
\text { Wyeth/Pfizer }\end{array}$ & No & $\begin{array}{l}\text { Yes: Abbott, } \\
\text { Amgen, } \\
\text { Wyeth/Pfizer }\end{array}$ & $\begin{array}{l}\text { Yes: Abbott } \\
\text { Amgen, BMS } \\
\text { Schering/Merck } \\
\text { Roche, UCB } \\
\text { Wyeth/Pfizer }\end{array}$ & No \\
\hline $\begin{array}{l}\text { Hazlewood, } \\
\text { Glen }\end{array}$ & No & No & No & No & No & $\begin{array}{l}\text { Yes: } \\
\text { UCB/CRATTAS } \\
\text { Fellowship Award }\end{array}$ & $\begin{array}{l}\text { Yes: } \\
\text { Abbott }\end{array}$ & No \\
\hline $\begin{array}{l}\text { LeClerq, } \\
\text { Sharon }\end{array}$ & $\begin{array}{l}\text { Yes: } \\
\text { Visser } 2009\end{array}$ & No & No & No & No & Yes: Roche & $\begin{array}{l}\text { Yes: Abbott } \\
\text { Amgen, Wyeth, } \\
\text { LRoche }\end{array}$ & No \\
\hline $\begin{array}{l}\text { Légaré, } \\
\text { Jean }\end{array}$ & No & No & No & No & No & No & No & No \\
\hline $\begin{array}{l}\text { Khraishi, } \\
\text { Majed }\end{array}$ & $\begin{array}{l}\text { Yes: } \\
\text { Bykerk } 2004\end{array}$ & No & No & No & No & $\begin{array}{l}\text { Yes: Abbott, UCB, } \\
\text { Amgen, Wyeth, } \\
\text { BMS, Roche, } \\
\text { Schering Plough }\end{array}$ & $\begin{array}{l}\text { Yes: Abbott } \\
\text { Amgen, Wyeth, } \\
\text { Schering, UCB, } \\
\text { Roche, BMS }\end{array}$ & No \\
\hline $\begin{array}{l}\text { Mosher, } \\
\text { Diane }\end{array}$ & $\begin{array}{l}\text { Yes: } \\
\text { Visser } 2009\end{array}$ & No & No & No & No & $\begin{array}{l}\text { Yes: Amgen, } \\
\text { Wyeth }\end{array}$ & $\begin{array}{l}\text { Yes: Abbott, } \\
\text { Pfizer }\end{array}$ & $\begin{array}{l}\text { Yes: Co-chair of } \\
\text { ACAP, which } \\
\text { receives money } \\
\text { from Abbott, } \\
\text { Amgen, Wyeth, } \\
\text { Roche, Pfizer, } \\
\text { Schering }\end{array}$ \\
\hline $\begin{array}{l}\text { Pencharz, } \\
\text { James }\end{array}$ & No & No & No & No & No & No & No & No \\
\hline $\begin{array}{l}\text { Pope, } \\
\text { Janet E. }\end{array}$ & $\begin{array}{l}\text { Yes: } \\
\text { Visser } 2009\end{array}$ & No & No & $\begin{array}{l}\text { Yes: Abbott, } \\
\text { Amgen, BMS, } \\
\text { Merck, UCB, } \\
\text { Roche, Wyeth, } \\
\text { Pfizer, Schering, } \\
\text { Actelion, GSK, } \\
\text { Medimmune, } \\
\text { Mediquest }\end{array}$ & No & $\begin{array}{l}\text { Yes: Pfizer, } \\
\text { BMS, Amgen, } \\
\text { Abbott, UCB, } \\
\text { Roche, Novartis, } \\
\text { Biogen, Celgene, } \\
\text { Genentech, GSK, } \\
\text { Medimmune, } \\
\text { Novartis, } \\
\text { Mediquest }\end{array}$ & $\begin{array}{l}\text { Yes: Pfizer, } \\
\text { BMS, Amgen, } \\
\text { Abbott, UCB, } \\
\text { Roche, Actelion, } \\
\text { Medimmune, } \\
\text { Merck, GSK }\end{array}$ & $\begin{array}{l}\text { Yes: CDN } \\
\text { Rheumatology } \\
\text { Research } \\
\text { Consortium }\end{array}$ \\
\hline Schieir, Orit & No & No & No & No & No & No & No & No \\
\hline $\begin{array}{l}\text { Thomson, } \\
\text { John }\end{array}$ & $\begin{array}{l}\text { Yes: } \\
\text { Visser } 2009\end{array}$ & No & No & No & No & Yes: Schering & $\begin{array}{l}\text { Yes: Schering, } \\
\text { Abbott, Amgen, }\end{array}$ & No \\
\hline $\begin{array}{l}\text { Thorne, } \\
\text { Carter }\end{array}$ & No & No & No & $\begin{array}{l}\text { Yes: Abbott, } \\
\text { Amgen, BMS, } \\
\text { Schering/Merck, } \\
\text { Roche, UCB, } \\
\text { Wyeth/Pfizer }\end{array}$ & No & $\begin{array}{l}\text { Yes: Abbott } \\
\text { Amgen, BMS, } \\
\text { UCB, Centocor, } \\
\text { Roche } \\
\text { Schering/Merck } \\
\text { Wyeth/Pfizer }\end{array}$ & $\begin{array}{l}\text { Yes: Abbott, } \\
\text { Amgen,Roche, } \\
\text { Schering/Merck, } \\
\text { Wyeth/Pfizer }\end{array}$ & $\begin{array}{l}\text { Yes: 1) CDN } \\
\text { Rheumatology } \\
\text { Research } \\
\text { Consortium } \\
\text { 2) Ontario } \\
\text { Rheumatology } \\
\text { Association } \\
\text { liaison with } \\
\text { Ontario Ministry } \\
\text { of Health Drug } \\
\text { Programs Branch }\end{array}$ \\
\hline $\begin{array}{l}\text { Zummer, } \\
\text { Michel }\end{array}$ & No & No & No & No & No & $\begin{array}{l}\text { Yes: Abbott, } \\
\text { Amgen, Roche }\end{array}$ & $\begin{array}{l}\text { Yes: Abbott, UCB, } \\
\text { Amgen, BMS, } \\
\text { Schering/Merck, } \\
\text { Pfizer/Wyeth, } \\
\text { Roche }\end{array}$ & No \\
\hline
\end{tabular}

